\title{
Comportamento mecânico de material fresado após processo de estabilização granulométrica e química por meio da incorporação de cimento e cinza de casca de arroz moída
}

\author{
Mechanical behavior of reclaimed asphalt \\ after grading and chemical stabilization \\ process through the incorporation of \\ cement and rice husk ash
}

Gustavo Menegusso Pires ${ }^{1}$, Luciano Pivoto Specht ${ }^{2}$, Rinaldo José Barbosa Pinheiro ${ }^{3}$, Deividi da Silva Pereira ${ }^{4}$, Eduardo Martins Renz ${ }^{5}$

\footnotetext{
${ }^{1}$ University of Nottingham, Nottingham Transportation Engineering Centre, University Park, Nottingham, Reino Unido email:gmenegussopires@gmail.com

2345 Universidade Federal de Santa Maria, Departamento de Transportes, Av. Roraima, 1000, Santa Maria, RS. e-mail: luspecht@ufsm.br²; rinaldo@ufsm.br ; dsp@ufsm.br ${ }^{4}$; eduardorenz@msn.com
}

\section{RESUMO}

Este trabalho objetivou avaliar, através de ensaios laboratoriais, a viabilidade da utilização de material fresado puro e estabilizado (mecânica, granulométrica e quimicamente) em camadas de pavimentos flexíveis. Os materiais fresados são oriundos da BR-290 e da ERS-509 no estado do Rio Grande do Sul. Foi realizada estabilização granulométrica, sendo determinado o teor de $70 \%$ de material fresado e $30 \%$ de agregado natural, sendo bastante efetiva na elevação do ISC (de 56 para 95\% e de 21 para 68\%, para o fresado da BR-290 e ERS-509). Para os ensaios compressão simples foram moldados corpos-de-prova cilíndricos de $10 \times 20 \mathrm{~cm}$ com diferentes teores de cimento Portland (CP-IV 32), sendo determinados os teores de 4,86\% (BR-290) e 5,37\% (ERS-569) a partir da resistência à compressão de 2,1 MPa aos 28 dias. A partir dos resultados obtidos, em uma segunda etapa da pesquisa utilizando somente o material fresado da ERS-509, foram moldados corpos de prova para determinação da resistência à compressão, da resistência à tração e do módulo de resiliência; sendo nestes substituído, em massa, o CP-IV em 15, 30 e 50\% por cinza de casca de arroz moída (\#325 e \#500), colocados em câmara úmida por 7, 28 e 160 dias. A análise dos resultados mostrou que para compressão simples e à tração, a substituição de $15 \%$ de cimento por CCA se mostrou eficiente, não havendo queda de resistência comparado as amostras de referência. Também fica evidente a eficácia da CCA, apresentando resultados positivos sempre que comparados àquelas misturas somente com o real teor de cimento Portland utilizado, juntamente com o apelo ambiental se torna uma alternativa interessante de utilização em camadas de pavimentos.

Palavras-chave: pavimento, estabilização, fresado, cimento, cinza de casca de arroz.

\section{ABSTRACT}

This research aims to evaluate, through laboratory testing, the feasibility of using pure and stabilized reclaimed asphalt pavement (mechanical, chemical and grading) in layers of flexible pavements. The milled materials are from BR-290 and ERS-509 roadways. Grading stabilization was performed and determined the level of $70 \%$ of milled material and $30 \%$ of virgin aggregate. For testing of compressive strength were molded into test specimens of 10x20 cm with different levels of Portland cement (CP IV-32), and determine the content of 4,86\% (BR-290) and 5,37\% (ERS-569) from the compressive strength of $2.1 \mathrm{MPa}$ at 28 days. From these results, specimens were molded for testing the axial compressive strength, indirect tensile strength and resilient modulus; in these specimens, the cement was replaced by rice husk ash (mesh \#325 and \#500) in ratios of 15, 30 and 50\% by weight of cement content, and put into moist chamber for 7, 28 and 160 curing days. The results showed that for compressive and tensile strength, the replacement of $15 \%$ of cement 
by CCA was efficient, with no drop resistance compared to the reference samples. Also evident the effectiveness of CCA, showing positive results when compared to those mixes only with the real content of Portland cement used and with the environmental appeal becomes an interesting alternative for use in pavement layers.

Keywords: paving, recycling, RAP, Portland cement, rice husk ash.

\section{INTRODUÇÃO}

A rodovia, e em especial o pavimento, em relação à importância do transporte no complexo da atividade socioeconômica, dentro de uma perspectiva de longo prazo (de ordem de grandeza, por exemplo, secular) deve apresentar permanentemente um desempenho satisfatório. Esse desempenho se traduz na oferta, ao usuário, de condições de tráfego seguras, confortáveis e econômicas - atendendo aos preceitos de otimização do custo total de transporte [1].

Segundo a Confederação Nacional do Transporte - CNT [2], rodovias que apresentam algum tipo de comprometimento do pavimento aumentam o consumo de combustível e contribuem para uma maior emissão de poluentes. Uma rodovia em bom estado de conservação pode resultar em até $5 \%$ de economia no consumo de combustível em relação a uma rodovia com estado de conservação inadequado.

Ao longo do período de uso das vias, a degradação dos pavimentos é inevitável, a qual está associada ao alto volume de tráfego e também ao considerável número de veículo que operam com cargas acima dos limites estabelecidos legalmente. Isso resulta muitas vezes na necessidade de intervenções de restauração das rodovias. Toda e qualquer intervenção para restauração de pavimentos tem como objetivo preparar a estrutura e a superfície do pavimento para resistir à ação das intempéries e das cargas do tráfego atuantes durante um novo ciclo de vida útil, garantindo a segurança, o conforto e a economia projetada para os usuários da rodovia nesse período.

A crescente conscientização do emprego correto dos recursos naturais, da necessidade da preservação ambiental e redução das emissões de poluentes tem impulsionado a busca de alternativas ambientalmente favoráveis. Ainda que as técnicas aplicáveis devam obedecer a questões como a maior durabilidade e a preservação das rodovias, ao tratar das questões ambientais com seu devido merecimento, essas já podem ser enquadrados à frente das demais. Com isso, os métodos de reciclagem de pavimentos têm ganhado a simpatia dos órgãos de gestão e da sociedade, por serem alternativas técnicas politicamente corretas e economicamente viáveis.

Aliados à técnica, os métodos de estabilização dos materiais são comumente utilizados na aplicação em camadas de pavimentos. A estabilidade da estrutura de uma rodovia depende da resistência dos materiais selecionados, adequadamente compactados e drenados. As propriedades de um material podem ser alteradas de várias maneiras, entre as quais estão incluídos os tratamentos químicos, térmicos, mecânicos e de outros meios. A estabilidade mecânica depende em sua grande maioria dos materiais utilizados, onde o processo de compactação resulta em aumento de densidade e consequentemente uma melhora no comportamento mecânico do material [3].

A estabilização em pavimentos é direcionada, além do subleito, para as camadas sob o revestimento utilizado, como bases e sub-bases. YODER e WITCZAK [4] comentam a importância da estabilização granulométrica, onde a estabilidade das misturas também depende do arranjo granular dos materiais.

Quando um material ou uma combinação de materiais com estabilidade mecânica adequada não pode ser obtida, ou onde a resistência deve ser melhorada, é aconselhável considerar a estabilização também por meio da adição de estabilizantes químicos [3,4]. Os principais materiais de cimentação que podem ser usados incluem o cimento Portland, cal, cinzas volantes e materiais betuminosos [3, 4, 5]. O cimento Portland é o agente cimentante utilizado em maior escala e com maior sucesso. Ele pode ser utilizado para camadas de bases e de sub-bases de todos os tipos. Ainda, sua aplicação pode ser dada em solos granulares, arenosos, siltosos e argilas.

Na estabilização com cimento, a mistura intensiva e a compactação do solo úmido com pó de cimento seco dão bons resultados especialmente em solos de menor coesão, em solos coesos como argila as vantagens podem ser obtidas por adição de cal durante a compactação da superfície [6].

Com o passar dos anos cada vez mais pesquisas sobre reciclagem de pavimentos têm sido elaboradas [7, 8, 9, 10, 11, 12, 13]. Ao tratar da reutilização dos materiais disponíveis, como o material asfáltico fresado, e tentar encontrar métodos eficazes de aplicação, surgem outros componentes que podem se tornar importantes. Os estudos avançados em concreto mostram a possibilidade de substituição do cimento Portland pela Cinza de Casca de Arroz - CCA [14, 15], o que nos acena como mais um caminho a ser seguido para estudo em pavimentação. A utilização da CCA em misturas também contribuirá com a reutilização desse material 
que poderia ter destinação inadequada, devido a disponibilidade desse material principalmente no Estado do Rio Grande do Sul, mas que se corretamente aplicado pode apresentar resultados satisfatórios.

Atualmente existem poucos trabalhos sobre a utilização da CCA como aditivo para estabilização de camadas de pavimentos. A CCA, de acordo com os pesquisadores [16, 17, 18, 19, 20], deve ser utilizada como aditivo a outro material já adicionado para estabilização ou melhoria da mistura em estudo, para que ocorram as reações pozolânicas necessárias. Os materiais mais utilizados em conjunto com a CCA são o cimento Portland e a cal hidratada.

O material passível de fresagem está disponível em diversas obras de restauração de pavimentos asfálticos, sendo um material envelhecido que perdeu muitas de suas propriedades. Dessa forma, se torna pertinente estudar o potencial de utilização como material granular para pavimentação. As principais questões a serem respondidas nesta pesquisa são acerca da utilização do material fresado em camadas de pavimentos e da utilização da CCA junto ao cimento Portland para estabilização química de materiais granulares, através da avaliação por ensaios laboratoriais como determinação das Resistências à Compressão Simples e à Tração por Compressão Diametral e determinação dos Módulos Resilientes.

\section{MATERIAIS E MÉTODOS}

No desenvolvimento do trabalho foram realizados diversos ensaios, tanto no material fresado como nas misturas estabilizadas, com o objetivo de determinar propriedades da engenharia que fossem relevantes. A figura 1 apresenta um fluxograma com o detalhamento de cada etapa na sequência.

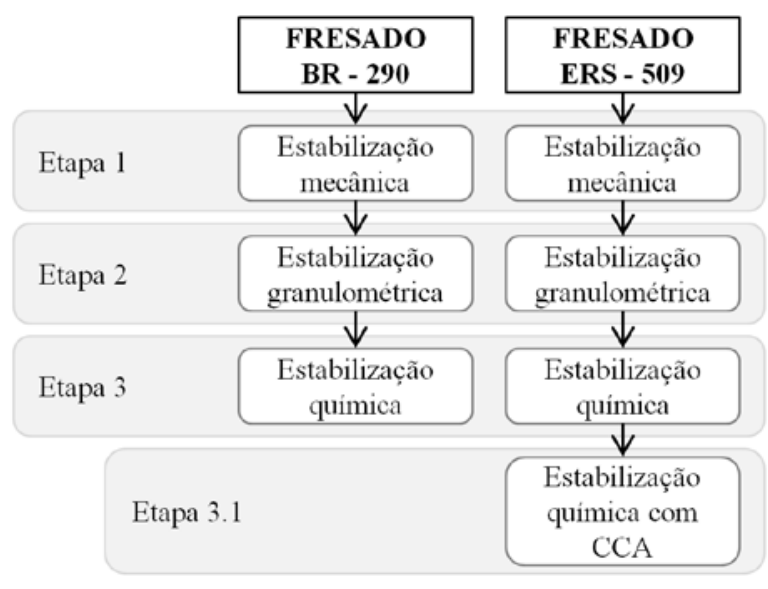

Figura 1: Fluxograma das etapas da pesquisa.

No estudo foram testadas três possibilidades de estabilização do material fresado:

Etapa 1: A primeira etapa consiste na estabilização mecânica, onde os materiais fresados de ambas as rodovias são compactados na forma na qual foram extraídos do pavimento, sem adição de outros materiais. Para esta etapa foram realizados ensaios de compactação e determinação do Índice de Suporte Califórnia e os resultados servem de comparativo para a etapa seguinte.

Etapa 2: A estabilização granulométrica consiste em fracionar os materiais disponíveis com o objetivo de atender às especificações de bases estabilizadas granulometricamente. Para essa etapa foram obtidas misturas contendo material fresado e agregados virgens (britas comerciais), e assim como a primeira etapa, foram realizados ensaios de compactação e determinação do Î́ndice de Suporte Califórnia de cada mistura.

Etapa 3: Com os resultados obtidos nos ensaios da Etapa 2, as misturas estabilizadas granulometricamente foram submetidas à estabilização química com a utilização de cimento Portland. Para essa etapa foram moldados corpos de prova cilíndricos de 10x20 cm com diferentes teores de cimento Portland, para então serem submetidos ao ensaio de Resistência à Compressão Simples (RCS). A forma de aplicação do agente cimentante foi por substituição em massa dos agregados da mistura. A tabela 1 apresenta o número de corpos de prova com suas respectivas percentagens de cimento Portland e tempo de cura em câmara úmida.

Tabela 1: Número de CP’s para determinação do teor ideal de cimento a partir de ensaios de RCS. 
PIRES, G.M.; SPECHT, L.P.; PINHEIRO, R.J.B.P.; PEREIRA, D.S.; RENZ, E.M. revista Matéria, v.21, n.2, pp. 365 - 384, 2016.

\begin{tabular}{c|c|c|c}
\hline TEOR DE CIMENTO & DIAS DE CURA & BR-290 & ERS-509 \\
\hline \multirow{2}{*}{$2 \%$} & 7 & 3 & - \\
\cline { 2 - 4 } & 28 & 3 & - \\
\hline \multirow{2}{*}{$3 \%$} & 7 & 3 & 3 \\
\cline { 2 - 4 } & 28 & 3 & 3 \\
\hline \multirow{2}{*}{$4 \%$} & 7 & 3 & 3 \\
\cline { 2 - 4 } & 28 & 3 & 3 \\
\hline \multirow{2}{*}{$5 \%$} & 7 & 3 & 3 \\
\cline { 2 - 4 } & 28 & 3 & 3 \\
\hline \multirow{2}{*}{$6 \%$} & 7 & - & 3 \\
\cline { 2 - 4 } & 28 & - & 24 \\
\hline \multirow{2}{*}{ Total } & - & 24 & 3 \\
\hline
\end{tabular}

Devido à sequência de moldagens, os corpos de prova com $2 \%$ de cimento Portland e material fresado da ERS-509 foram substituídos por corpos de prova com teor de 6\%, pois as amostras com 2\% nas misturas do material fresado da BR-290 se mostraram muito frágeis quando retiradas dos moldes.

Etapa 3.1: Esta etapa é uma sequência da Etapa 3, onde a estabilização química é testada com a utilização de CCA em substituição parcial do cimento Portland. Devido a alta quantidade de ensaios laboratoriais, essa fase foi realizada apenas para a mistura com material fresado da rodovia ERS-509. A partir dos resultados encontrados na Etapa 3, foi determinado o teor de cimento Portland para realizar a substituição deste pela CCA.

Para essa etapa os corpos de prova foram moldados para ensaios de determinação de RCS, Resistência à Tração por Compressão Diametral (RTCD) e Módulo de Resiliência (MR), em três idades diferentes, 7, 28 e 160 dias de cura em câmara úmida. Também foram determinadas 3 substituições em massa do cimento Portland pela CCA (15, 30 e 50\%), para cada finura da CCA, \#325 e \#500. Em cada dosagem foram moldados 3 corpos de prova para obtenção dos resultados, totalizando 183 amostras nessa fase.

\subsection{Material fresado}

Foram coletados materiais oriundos de duas rodovias no estado do Rio Grande do Sul que estavam em processo de manutenção, ambos os revestimentos concreto asfáltico por origem:

Rodovia Federal BR-290: O material fresado utilizado na etapa laboratorial foi coletado na BR-290, pista Norte, durante o processo de manutenção do pavimento asfáltico em julho de 2012 nas proximidades do acesso a cidade de Cachoeirinha. Foram feitas 6 coletas, em pares, diretamente da esteira da máquina fresadora e enviados para o Laboratório de Materiais de Construção Civil (LMCC) da UFSM.

Rodovia Estadual ERS-509: O material fresado foi coletado na ERS-509 durante o processo de manutenção do pavimento asfáltico em outubro de 2011, nas proximidades do km 06, trecho entre Camobi e Santa Maria/RS. Cerca de $6 \mathrm{~m}^{3}$ de material foram coletados e depositados junto ao LMCC da UFSM.

Cada uma das amostras coletadas foi seca ao ar, quarteada e preparada para ensaios de caracterização: granulometria [21], percentagem de betume em misturas betuminosas [22], determinação da massa específica pela metodologia Rice [23], além de granulometria após a extração do ligante. O procedimento de quarteamento foi repetido sempre que utilizado cada material fresado com objetivo de homogeinização das amostras.

\subsubsection{Material fresado BR-290}

A figura 2 apresenta os valores plotados da análise granulométrica realizada com o fresado da BR-290. As amostras foram separadas em 3 pares, devido a coleta do material ter sido realizada em diferentes pontos do trecho restaurado. Na figura 2 também é apresentada a distribuição granulométrica das amostras após a extração do ligante asfáltico, para melhor análise de variações na granulometria. Para cada situação os resultados foram agrupados gerando duas curvas de distribuição, uma anterior e outra posterior a extração do betume. 


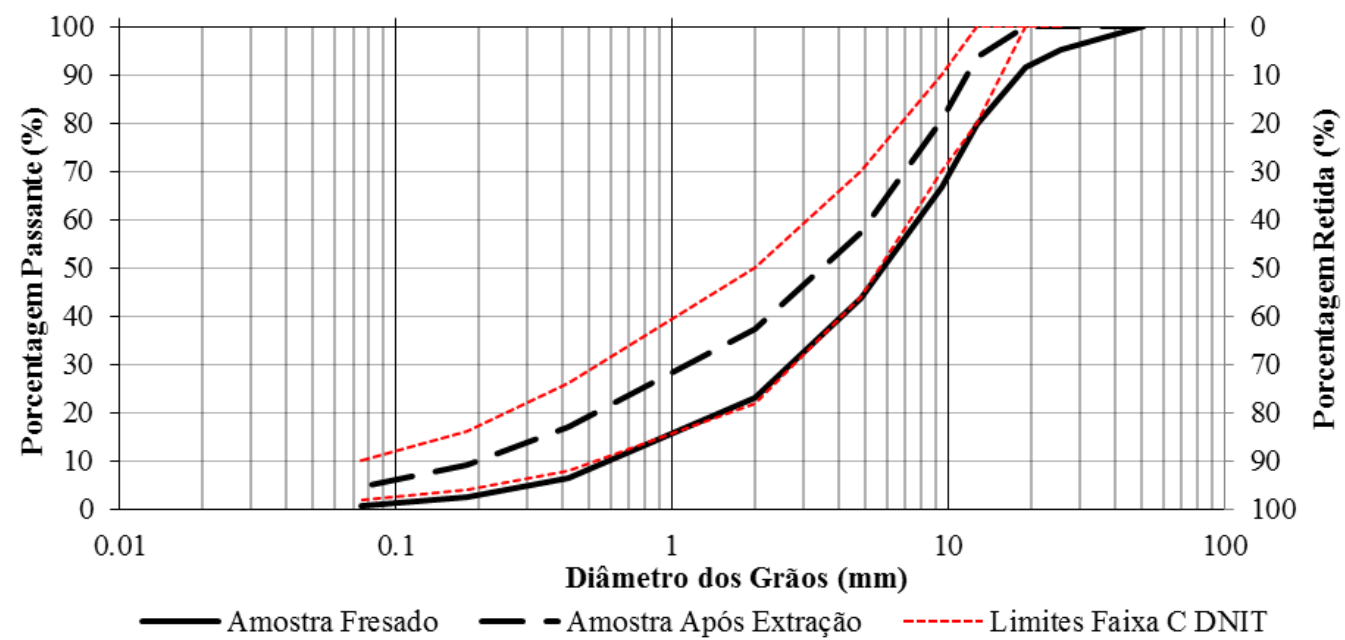

Figura 2: BR 290 - Distribuição granulométrica do material fresado.

A análise comparativa das curvas nos mostra, como era de se esperar, redução do tamanho dos grãos (grumos) pela desagregação causada pela ausência de ligante. A granulometria do concreto asfáltico utilizado pela Concessionária foi, historicamente, a faixa IV-B do Instituto do Asfalto e a Faixa C do Departamento Nacional de Infraestrutura de Transportes - DNIT [24], cujos diâmetros máximos de agregados granulares são de 19mm (3/4”), compatível com os resultados encontrados.

Foi encontrado o teor de betume médio das amostras, igual a 5,00\%, com desvio padrão de 0,33\%. O valor é bastante coerente com os projetos de concreto asfáltico executados na região de estudo devido à origem mineralógica dos agregados, rochas vulcânicas (dacitos), com absorção aproximadamente em 1,5\%. A Densidade Máxima Medida - DMM, obtida no ensaio para determinação da massa específica real pela metodologia Rice [16], foi igual a $2,505 \mathrm{~g} / \mathrm{cm}^{3}$. Os valores desse ensaio de caracterização são influenciados pela composição da mistura asfáltica em termos de tipo e quantidade de materiais agregados e betuminosos.

\subsubsection{Material fresado ERS-509}

A figura 3 apresenta os valores plotados da análise granulométrica feita com o fresado da ERS-509. A distribuição granulométrica das amostras após a extração do ligante asfáltico também é apresentada.

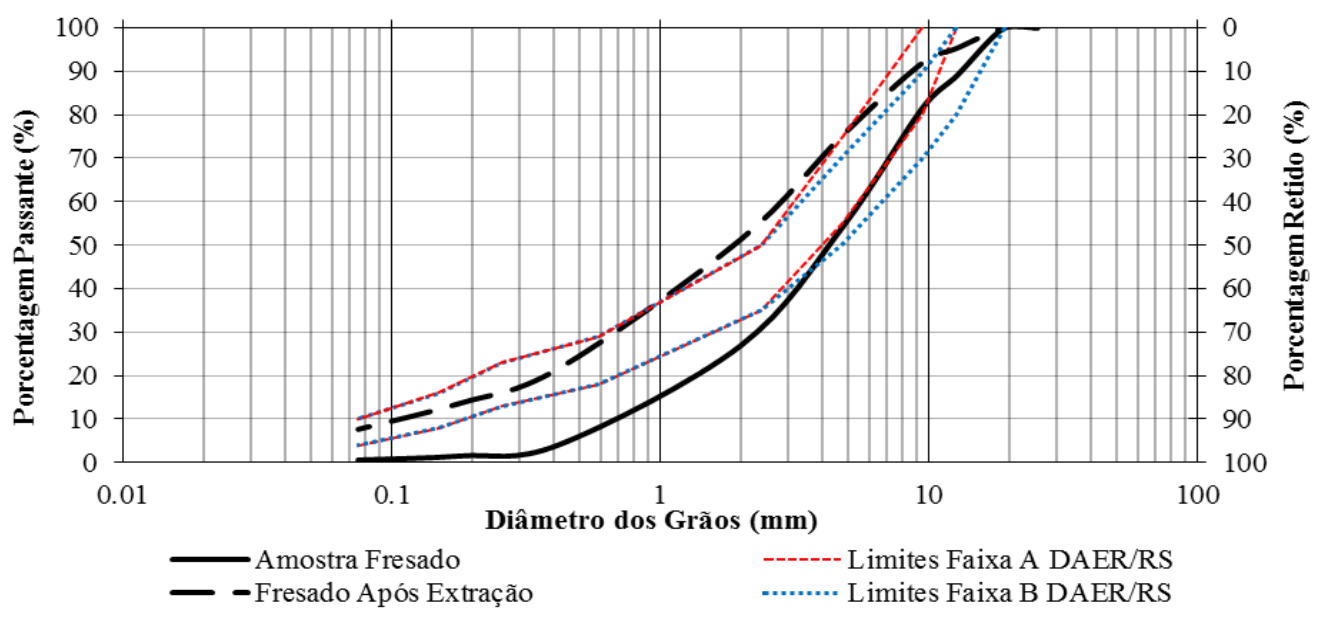

Figura 3: ERS 509 - Distribuição granulométrica do material fresado.

O material fresado da ERS-509 utilizado na pesquisa foi passado na Peneira 3/4”a fim de descartar os grumos do material e estabilizá-lo granulometricamente.

Na tentativa de enquadrar o material nas faixas granulométricas de projeto especificadas pelo Depar- 
tamento Autônomo de Estradas de Rodagem - DAER [25] para concreto asfáltico houve pequena discrepância nos valores, principalmente nos agregados com dimensões entre 0,5 e $4 \mathrm{~mm}$ de diâmetro. Além disso, é possível perceber que os materiais finos se encaixam nas faixas A e B do DAER, o que não ocorre quando os grãos aumentam a partir de $4 \mathrm{~mm}$, passando da Faixa A para B nos agregados maiores que $10 \mathrm{~mm}$ de diâmetro. Após análise entre as curvas das amostras antes e após a extração do ligante asfáltico, houve redução do tamanho dos grãos causado pela desagregação dos grumos de fresado pela ausência do ligante. Ao analisar as curvas originais de ambas as misturas asfálticas (BR-290 e ERS-509) é possivel constatar a maior presença de materiais finos no segundo caso, o que indica um arranjo granulométrico capaz de suportar menor volume de tráfego, em relação ao primeiro caso apresentado.

Determinou-se o teor de betume médio das amostras do material fresado ERS-509, sendo este igual a $6,06 \%$, com desvio padrão de $0,31 \%$ entre as amostras. O teor apresentou um grau percentual acima do valor encontrado para o material da BR-290, o que pode ser explicado pela utilização de agregados virgens de pedreiras distintas, mas não se distancia dos padrões usuais de dosagem de concreto asfáltico da região, que necessitam de maior teor de ligante devido à origem mineralógica dos agregados, rochas vulcânicas ácidas (riodacitos), com absorção entre 2 e 2,7\%. Os resultados obtidos no ensaio para determinação da massa específica real dos grãos foi de DMM igual a $2,370 \mathrm{~g} / \mathrm{cm}^{3}$, o que também pode ser explicado pela origem dos agregados virgens utilizados.

\subsection{Agregados}

Os agregados virgens utilizados nas misturas com fresado da BR-290 são provenientes da Pedreira do Consórcio Construtor TRS localizada as margens da rodovia BR-290 em Santo Antônio da Patrulha/RS. Trata-se de um agregado de origem vulcânica largamente utilizado para execução de Macadame Seco, Brita Graduada Simples e Concreto Asfáltico.

Os agregados virgens utilizados nas misturas com fresado da ERS-509 são provenientes da Brita Pinhal localizada na Estrada Morro do Baú - BR 158, Itaara/RS. Trata-se de um agregado de origem vulcânica utilizado para execução de Brita Graduada Simples, Macadame Seco, Concreto Asfáltico, Pré-misturados à frio e demais materiais granulares para utilização em pavimentação e obras civis. Apenas o pó-de-pedra foi utilizado como agregado virgem para as misturas com o material fresado da ERS-509.

\subsection{Cimento Portland}

O cimento utilizado na pesquisa foi o CP IV-32 - Cimento Portland Pozolânico. Sua composição é de silicatos de cálcio, aluminatos e ferro aluminatos, sulfato de cálcio, material carbonático e pozolana [26]. Uma vantagem do uso deste cimento é a redução do calor de hidratação e o aumento da resistência em idades avançadas, o que o torna recomendável na aplicação de grandes volumes de materiais e sob temperaturas elevadas . A tabela 2 apresenta resultados dos ensaios de caracterização do cimento utilizado.

Tabela 2: Características físicas do cimento.

\begin{tabular}{|c|c|c|c|}
\hline \multicolumn{2}{|r|}{ GRANDEZA FÍSICA } & RESULTADO & LIMITES NBR 5736 \\
\hline \multicolumn{2}{|c|}{ Finura \#200 (\%) [27] } & 2,42 & $<8,0$ \\
\hline \multicolumn{2}{|c|}{ Finura Blaine $\left(\mathrm{cm}^{2} / \mathrm{g}\right)$ [28] } & $3599 \pm 36$ & -- \\
\hline \multicolumn{2}{|c|}{ Massa específica $\left(\mathrm{g} / \mathrm{cm}^{3}\right)$ [29] } & 2,74 & -- \\
\hline \multicolumn{2}{|c|}{ Início de pega (mín) [30] } & 90 & $>60$ \\
\hline \multicolumn{2}{|c|}{ Fim de pega (mín) [30] } & 180 & -- \\
\hline \multirow{3}{*}{$\begin{array}{l}\text { Resistência Ar- } \\
\text { gamassa (MPa) } \\
{[31]}\end{array}$} & 3 dias & 21,49 & $>10,0$ \\
\hline & 7 dias & 25,82 & $>20,0$ \\
\hline & 28 dias & 33,57 & $32,0-49,0$ \\
\hline
\end{tabular}

O cimento utilizado foi submetido a uma análise química, sendo encontrados os seguintes componentes químicos em maior concentração: Óxido de cálcio $(\mathrm{CaO})$, Dióxido de silício $\left(\mathrm{SiO}_{2}\right)$, Óxido de alumínio $\left(\mathrm{Al}_{2} \mathrm{O}_{3}\right)$, Óxido de magnésio $(\mathrm{MgO})$ e Óxido de ferro $\left(\mathrm{Fe}_{2} \mathrm{O}_{3}\right)$.

\subsection{Cinza de casca de arroz (CCA)}

A CCA é um produto derivado da calcinação controlada e constante da casca de arroz em termoelétricas, com 
posterior industrialização. Esse produto é composto por até 95\% de Dióxido de Silício $\left(\mathrm{SiO}_{2}\right)$ com baixa quantidade de carbono e traços de metais.

A utilização da CCA, da mesma forma como o material fresado, carrega o apelo ambiental consigo, pelo reaproveitamento dos materiais. A CCA, sendo um material pozolânico, foi escolhida para que fossem realizadas substituições do cimento Portland das misturas, afim de que se pudesse diminuir o consumo deste cimento em possíveis aplicações em pavimentação.

Nesta pesquisa, foi utilizada CCA moída, apresentando duas finuras que são comercializadas pela empresa fornecedora do material, sendo então denominadas CCA \#325 e CCA \#500. A tabela 3 apresenta os resultados dos ensaios de caracterização física da CCA utilizada, realizados no LMCC da UFSM. A massa específica se mostrou muito semelhante, o que comprova que o material CCA\#500 apenas passou por processo de moagem por mais tempo que a CCA\#325, resultando em maiores superfícies específicas na finura Blaine e finura na peneira $\mathrm{n}^{\circ} 200$.

Tabela 3: Características físicas da CCA.

\begin{tabular}{l|c|c}
\hline GRANDEZA FíSICA & CCA\#325 & CCA\#500 \\
\hline Finura \#200 (\%) [27] & 0,1 & 0,08 \\
\hline Finura Blaine $\left(\mathrm{cm}^{2} / \mathrm{g}\right)[28]$ & $4238 \pm 42$ & $4728,55 \pm 47$ \\
\hline Massa específica $\left(\mathrm{g} / \mathrm{cm}^{3}\right)[29]$ & 2,086 & 2,083 \\
\hline
\end{tabular}

Na figura 4 é apresentado o difratograma de raios X da CCA, teste realizado na UFSM. Observa-se que a cinza demonstra comportamento de um material cristalino por apresentar picos no ensaio, típico da presença de cristais no material. Esse ensaio mostra que a queima da casca de arroz natural pode não ter sido realizada com controle adequado de temperatura por não se tratar de um material amorfo.

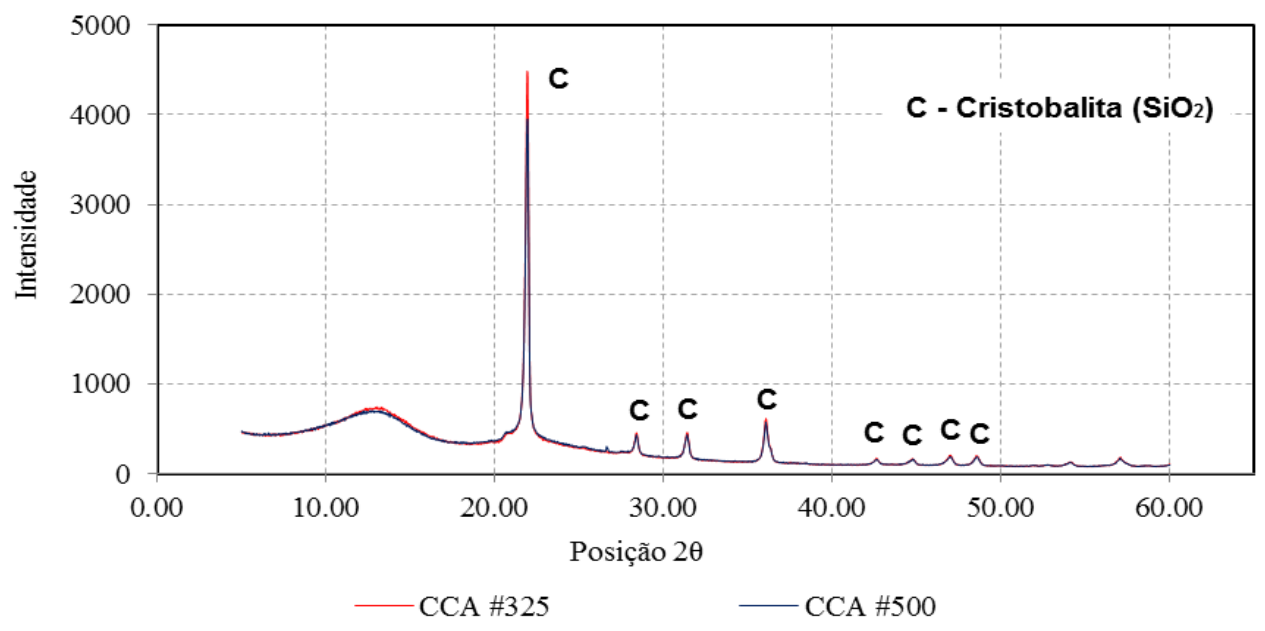

Figura 4: Difratograma CCA.

Para que não ocorra a formação de cristais são exigidas temperaturas abaixo de $600^{\circ} \mathrm{C}$, pois acima disso o sódio e o potássio, presentes na composição da cinza, aceleram a fusão das partículas e a cristalização da cristobalita a partir da sílica amorfa, diminuindo o ponto de fusão do material. Logo, para que haja a possibilidade de cristalização das partículas, a CCA deve ter sido submetida a temperaturas elevadas de queima, diminuindo as proporções de sílica amorfa [14, 15, 41].

\section{5 Água}

A água utilizada na preparação das amostras foi oriunda da rede hidráulica do LMCC da UFSM e é considerada potável. No entanto, determinados ensaios de caracterização se fez necessário a utilização de água destilada em atendimento às normas. 


\section{PROCEDIMENTOS EXPERIMENTAIS}

Foi realizada uma extensa campanha de ensaios laboratoriais para determinar a caracterização e variabilidade do fresado, determinação dos parâmetros de compactação e resistência do fresado, fresado estabilizado granulometricamente e fresado estabilizado química e granulometricamente.

\subsection{Ensaio de compactação}

Nesta pesquisa foi utilizada a energia Proctor modificada, conforme é prática para materiais granulares no estado do Rio Grande do Sul, e segue os preceitos da norma de solos para ensaio de compactação utilizando amostras trabalhadas [32]. A compactação foi realizada para as misturas estabilizadas granulometricamente e para o material fresado puro, tanto para os materiais da BR-290 como para os da ERS-509.

\section{2 Índice de Suporte Califórnia - ISC}

Assim como no ensaio de compactação, esse ensaio foi realizado para as misturas estabilizadas granulometricamente e para o material fresado puro para os materiais das duas rodovias em estudo. Esse ensaio seguiu os preceitos da norma para determinação do Índice de Suporte Califórnia utilizando amostras não trabalhadas [33], sendo o parâmetro ainda utilizado no método de dimensionamento de pavimentos flexíveis vigente no Brasil. Os resultados obtidos nos ensaios de compactação de cada material foram utilizados para determinação do ISC, onde as amostras foram compactadas nos teores de umidade ótimos encontrados em cada caso, valor esse correspondente a densidade máxima seca dos grãos.

\subsection{Resistência à compressão simples (RCS)}

Após o tempo de cura determinado, os corpos de prova de 10x20 cm foram submetidos a um esforço de compressão até sua ruptura. A norma utilizada na pesquisa foi a DNER - ME 180/1994 - Solos estabilizados com cinza volante e cal hidratada - Determinação da resistência à compressão simples [34].

\subsection{Resistência à tração por compressão diametral (RTCD)}

A norma utilizada como base para execução desse ensaio foi a DNIT - ME 136/2010 - Pavimentação asfáltica - Misturas asfálticas - Determinação da resistência à tração por compressão diametral - Método de ensaio [35]. Essa norma determina que o molde cilíndrico a ser utilizado tenha $10 \mathrm{~cm}$ de diâmetro interno e 6,3 cm de altura, com altura mínima da amostra de 3,5 cm.

\subsection{Modulo de resiliência (MR)}

O MR é reconhecido como de grande importância no dimensionamento de estruturas de pavimentos asfálticos, visto que condiciona a distribuição de esforços internos. Para determinação do MR de materiais asfálticos e cimentados, analisados nessa pesquisa, foram ensaiadas, dinamicamente, amostras diametrais, submetendo-as a tensões de tração por compressão diametral.

Os ensaios foram realizados no LMCC da UFSM e no Laboratório de Pavimentação (LAPAV) da Universidade Federal do Rio Grande do Sul (UFRGS). Ambos os equipamentos apresentam resultados de MR total, onde o cálculo é realizado a partir da deformação total medida no ensaio. As tensões utilizados no ensaio foram iguais a $10 \%$ do valor determinado de RTCD, item 3.4, para cada caso. A norma da American Society For Testing and Materials, ASTM D7369: Standard Test Method for Determining the Resilient Modulus of Bituminous Mixtures by Indirect Tension Test [36], foi utilizada na condução dos ensaios devido a configuração dos equipamentos.

\section{RESULTADOS E DISCUSSÃO}

A seguir são apresentados os resultados da pesquisa de acordo com a metodologia proposta.

\subsection{Estabilização mecânica e granulométrica}

A estabilização mecânica nesta pesquisa, ao realizar ensaios de compactação e ISC com os materiais fresados na sua forma natural de extração do pavimento, foram testados para obtermos parâmetros de resistência.

A dosagem da mistura ou estabilização granulométrica consistiu em fracionar os agregados disponíveis de maneira a atender alguma especificação, neste caso a especificação de base estabilizada granulometricamente do Departamento Nacional de Infraestrutura de Transportes DNIT 141/2010 - ES [37]. 


\subsubsection{Estabilização granulométrica BR-290}

Ao realizar o procedimento de enquadrar a mistura em faixa granulométrica do DNIT, ficou estabelecida a proporção de $70 \%$ de material fresado e $30 \%$ de agregado virgem. A faixa da mistura ficou dentro dos limites da Faixa A do DNIT, sendo o material virgem utilizado em 15\% de brita 3/4” e 15\% de pó de pedra.

Essa proporção chamada de 70/30 conjuga de maneira satisfatória a questão técnica e econômica. Com a utilização do material virgem foi possível manter a questão técnica ao estabelecer a mistura dentro da Faixa A. A figura 5 apresenta os resultados obtidos com a mistura 70/30.

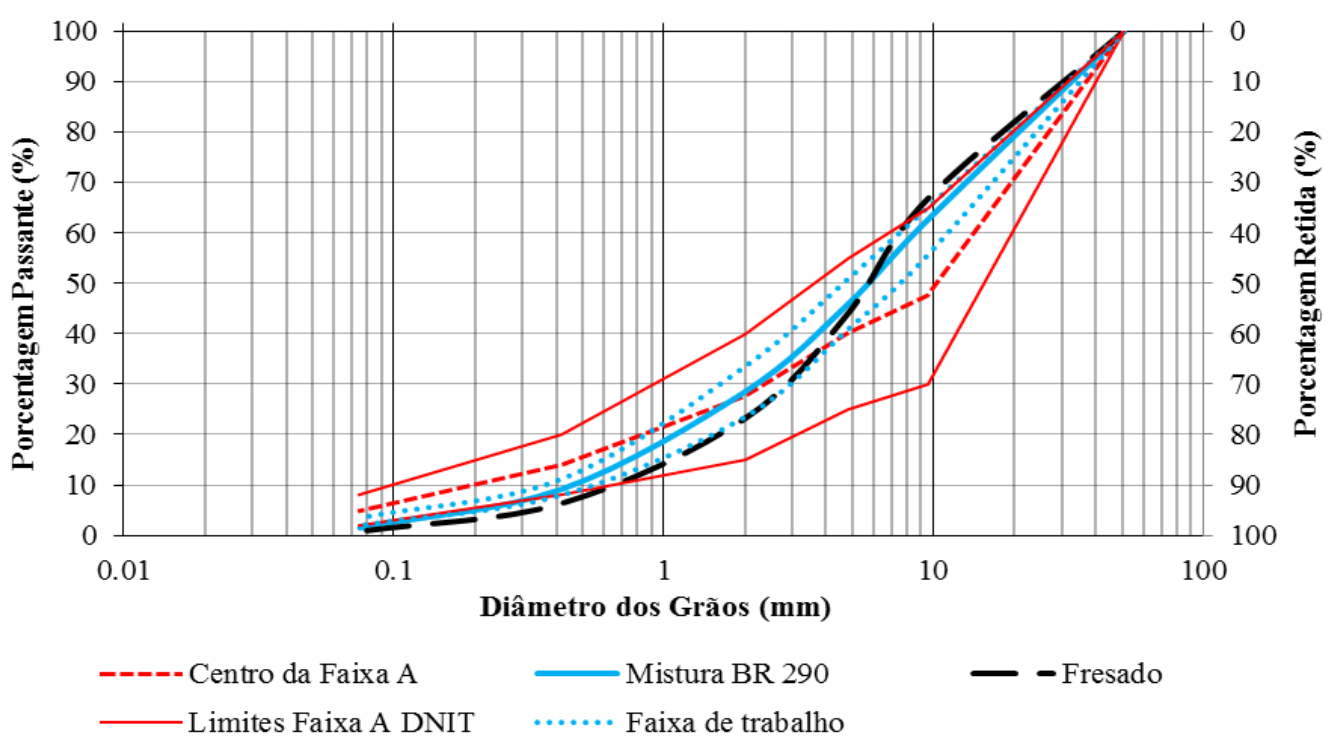

Figura 5: BR-290 - Projeto de estabilização granulométrica.

\subsubsection{Estabilização granulométrica - ERS-509}

Para a mistura com material fresado oriundo da ERS-509 também ficou estabelecida a proporção de 70\% de material fresado e $30 \%$ de agregado virgem. A faixa da mistura ficou dentro dos limites da Faixa C do DNIT [37] para base estabilizada granulometricamente, sendo o material virgem utilizado em 30\% de pó de pedra. A figura 12 apresenta os resultados obtidos com a mistura 70/30.

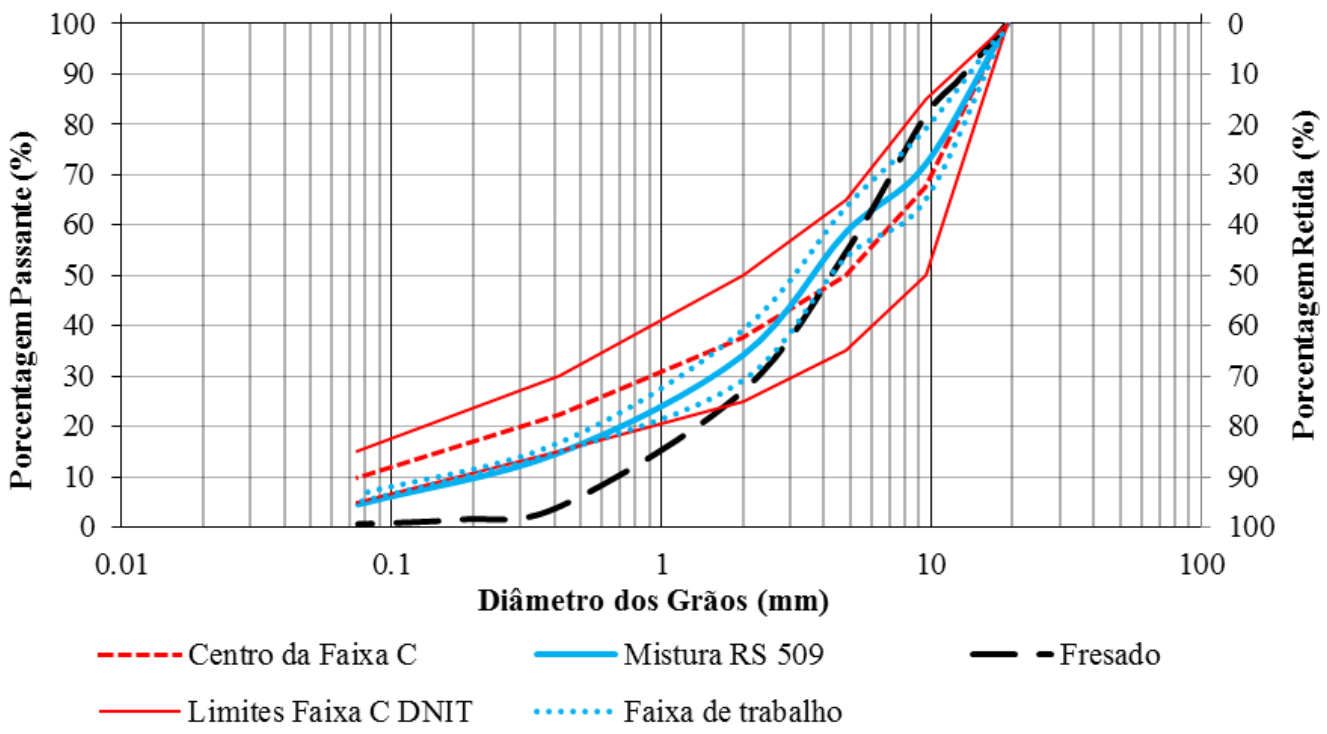

Figura 6: ERS-509 - Projeto de estabilização granulométrica. 
A granulometria original do material fresado da ERS-509 apresentava deficiência na quantidade de finos, em consequência disso se mostrou eficaz a adição do pó de pedra para estabilização. Sendo assim, a maior quantidade de finos da mistura é composta por material virgem, ficando o material fresado com toda parte da porção retida nas peneiras 3/8” e 4. Dessa forma foi possível estabelecer a mistura dentro dos limites da Faixa C do DNIT [37], com quantidade suficiente de finos.

\subsection{Compactação}

Os resultados de estabilização mecânica do material fresado e também das misturas estabilizadas granulometricamente são apresentados na figura 7. A análise dos resultados das curvas e dos parâmetros de compactação dos materiais em estudo permite afirmar que a adição do material virgem preenche os vazios do fresado em ambos os casos, o que é demonstrado pelo aumento do valor do $\gamma_{\text {dmáx }}$. Sendo esse aumento extremamente benéfico, uma vez que os materiais com índices de vazios mais baixos tendem a ter uma maior resistência ao cisalhamento e rigidez.

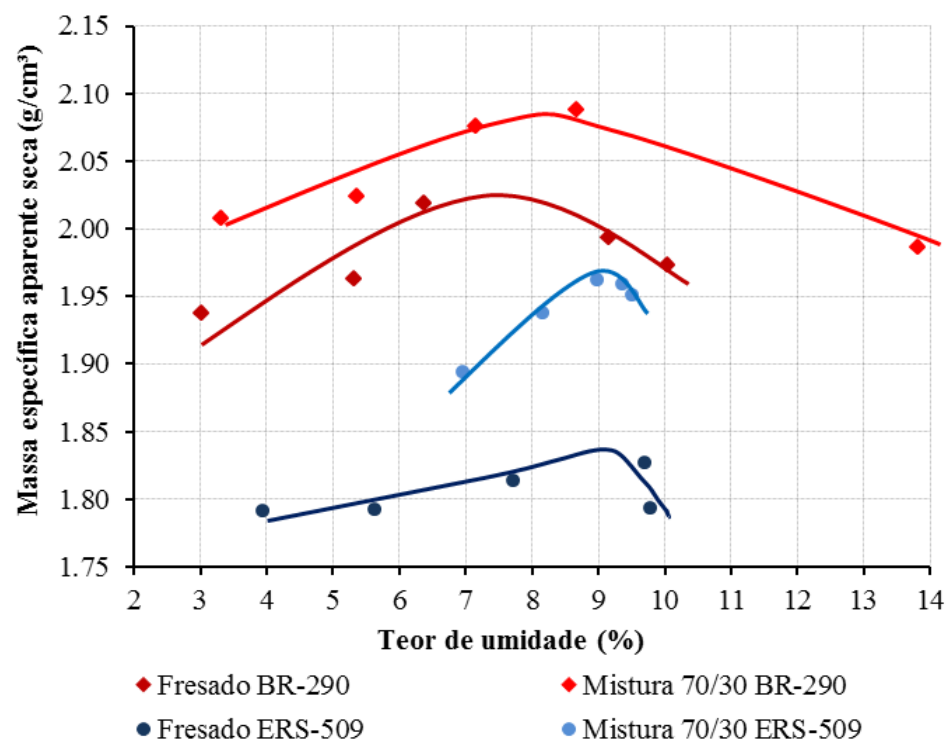

Figura 7: Curvas de compactação.

A comparação dos valores encontrados para o fresado com dados da literatura indicam pequena variação nos valores, no caso da massa específica aparente seca máxima do fresado da BR-290, 2,023g/ $\mathrm{cm}^{3}$ se aproxima de $2,1 \mathrm{~g} / \mathrm{cm}^{3}$ encontrado por SILVA [38]. Já o material fresado da rodovia ERS-509, 1,827g/ $\mathrm{cm}^{3} \mathrm{se}$ equipara com $1,798 \mathrm{~g} / \mathrm{cm}^{3}$ do trabalho de PINTO et al. [39]. Tais variações são bastante comuns, visto se tratarem de materiais de fontes distintas, e também pelo fato do fresado estar envolto pelo ligante asfáltico, sendo este um material hidrofóbico que dificulta o contato da água com os grãos.

Uma análise importante que diz respeito a ambas as misturas estabilizadas granulometricamente é a questão da reprodução desses resultados em campo. Como a forma de compactação em campo é por energia mecânica, há uma tendência de quebra do material fresado, principalmente nos maiores grãos formados por grumos de materiais de diâmetro menores. Devido à fragilidade desse material já envelhecido esta quebra torna a mistura mais fina e alteraria a curva de compactação original.

A influência da temperatura também é outro mecanismo que pode afetar diretamente o comportamento das misturas. Pela utilização de um material envolto ao ligante asfáltico, o calor pode ter impacto direto tanto no momento da compactação do material, quanto em um posterior aquecimento, uma vez que em temperaturas elevadas o poder cimentício do ligante asfáltico pode ser reestabelecido, mesmo que em baixo potencial. Dessa forma, seria ainda mais imprevisível analisar a quebra, ou não, do material fresado na compactação. 
PIRES, G.M.; SPECHT, L.P.; PINHEIRO, R.J.B.P.; PEREIRA, D.S.; RENZ, E.M. revista Matéria, v.21, n.2, pp. 365 - 384, 2016.

\section{3 Índice de Suporte Califórnia}

Os resultados dos ensaios de Índice de Suporte Califórnia (ISC) são apresentados na tabela 4.

Tabela 4: Resultados de ensaio de ISC para umidade ótima.

\begin{tabular}{c|l|c|c}
\hline \multicolumn{2}{|c|}{ MATERIAL } & EXPANSÃO & ISC (\%) \\
\hline \multirow{2}{*}{ BR-290 } & Fresado & 0 & 56 \\
\cline { 2 - 4 } & Mistura 70/30 & 0 & 95 \\
\hline \multirow{2}{*}{ ERS-509 } & Fresado & 0 & 21 \\
\cline { 2 - 4 } & Mistura 70/30 & 0 & 68 \\
\hline
\end{tabular}

Esses valores são típicos de solos grossos, pedregulhosos, do grupo G do Sistema Unificado de Classificação de Solos ou ainda dos grupos A1 e A2 da classificação do TRB (Transportation Research Board). Materiais com ISC nessa ordem de grandeza são tipicamente utilizados como sub-base, onde a exigência vigente é que o ISC seja maior que $20 \%$ e expansão inferior a $1 \%$, valores estes encontrados em todas as amostras ensaiadas. Pelos valores encontrados é possível utilizar alguns desses materiais em camadas de base de rodovias de menor volume de tráfego, onde são admitidos ISC $<60 \%$. Vale também mencionar a efetividade da estabilização granulométrica, para os dois fresados utilizados observam-se ganhos expressivos nos valores de ISC.

\subsection{Estabilização química com cimento}

A estabilização química foi avaliada pela moldagem de corpos de prova para ensaio de RCS, com 2, 3, 4, 5 e 6\% de cimento Portland CP IV-32, em cura úmida por 7 e 28 dias. Os parâmetros de compactação dos corpos de prova foram retirados dos resultados do ensaio de compactação das misturas estabilizadas granulometricamente. A incorporação do cimento se deu por substituição da massa seca do material. A figura 8 apresenta os resultados de resistência em função da quantidade de cimento.

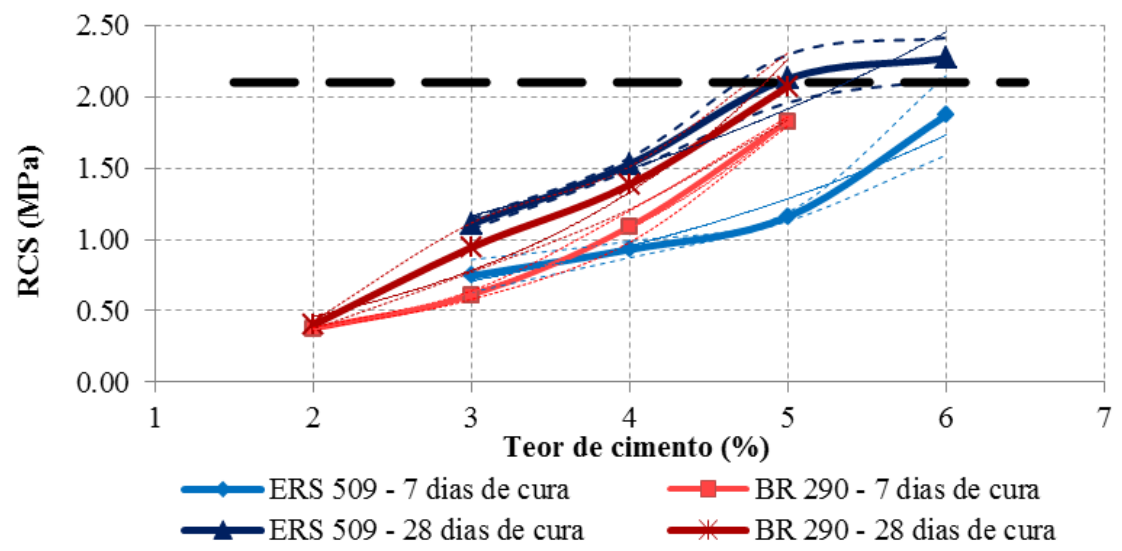

Figura 8: Teor de cimento x RCS (MPa).

As linhas tracejadas apresentam os valores acrescidos e subtraídos do desvio padrão e as linhas sólidas representam o ajuste matemático que descreve a tendência dos dados de cada curva. Ao fazer essa apresentação, é possível perceber a importância do tempo de cura no ganho de resistência.

Segundo as normas brasileiras sobre solo-cimento, o teor de cimento adotado deve ser aquele cuja resistência média à compressão simples seja igual ou superior a 2,1 MPa aos sete dias. Segundo tal prescrição o teor de cimento que deveria ser empregado, sem margem operacional, seria de 6,65\% (ERS-509) e 5,26\% (BR-290).

No caso de implantação de uma rodovia e dependendo das condições, é aceitável que ao invés de 7 dias de cura seja considerado 28 dias, quando as reações de cimentação estariam chegando a um patamar de estabilização e, nesse caso, de acordo com as curvas de tendência dos resultados de RCS da figura 8, o teor de cimento encontrado foi de 5,37\% para a mistura com fresado da ERS-509 e 4,86\% com fresado da BR290 , valores estes utilizados no decorrer da pesquisa. 


\subsection{Estabilização química com CCA}

Com os resultados obtidos (Item 4.4), foi fixado o teor de cimento de 5,37\% para substituição deste pela CCA conforme metodologia proposta. A estabilização química com a substituição do cimento Portland por CCA moída foi realizada apenas para a mistura estabilizada com material fresado oriundo da ERS-509. Para tanto, nessa estabilização, uma gama maior de ensaios foi realizada, a fim de avaliar alternativas ao uso do cimento na pavimentação, sem perda de eficiência técnica e com apelo sustentável.

A determinação dos teores utilizados para substituir o cimento pela CCA foi baseada na literatura nacional sobre concreto de cimento Portland [14, 15, 40]. Os avanços desta área da construção civil na utilização da CCA estão à frente no que diz respeito à aplicação em pavimentos. Como apresentado anteriormente, as percentagens utilizadas de CCA (15, 30 e 50\%) foram aplicadas nas misturas fazendo a substituição em massa do cimento Portland pela cinza de casca de arroz, conforme dados da tabela 5.

Tabela 5: Teores de cimento Portland e CCA nas misturas.

\begin{tabular}{c|c|c|c}
\hline CIMENTO PORTLAND (\%) & $\begin{array}{c}\text { CIMENTO PORTLAND NA } \\
\text { MISTURA (\%) }\end{array}$ & CCA (\%) & CCA NA MISTURA (\%) \\
\hline 100 & 5,37 & 0 & 0,00 \\
\hline 85 & 4,56 & 15 & 0,81 \\
\hline 70 & 3,76 & 30 & 1,61 \\
\hline 50 & 2,69 & 50 & 2,69 \\
\hline
\end{tabular}

As figuras 9 e 10 apresentam os resultados de RCS para as misturas estabilizadas com CCA \#325 e \#500, respectivamente.

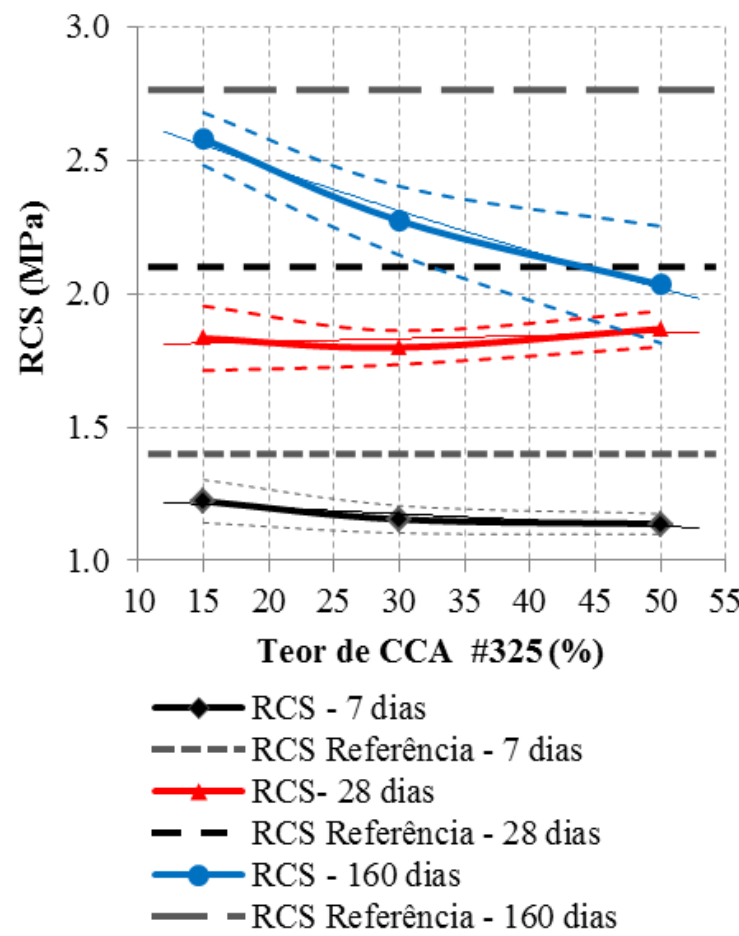

Figura 9: Teor de CCA \#325 x RCS.

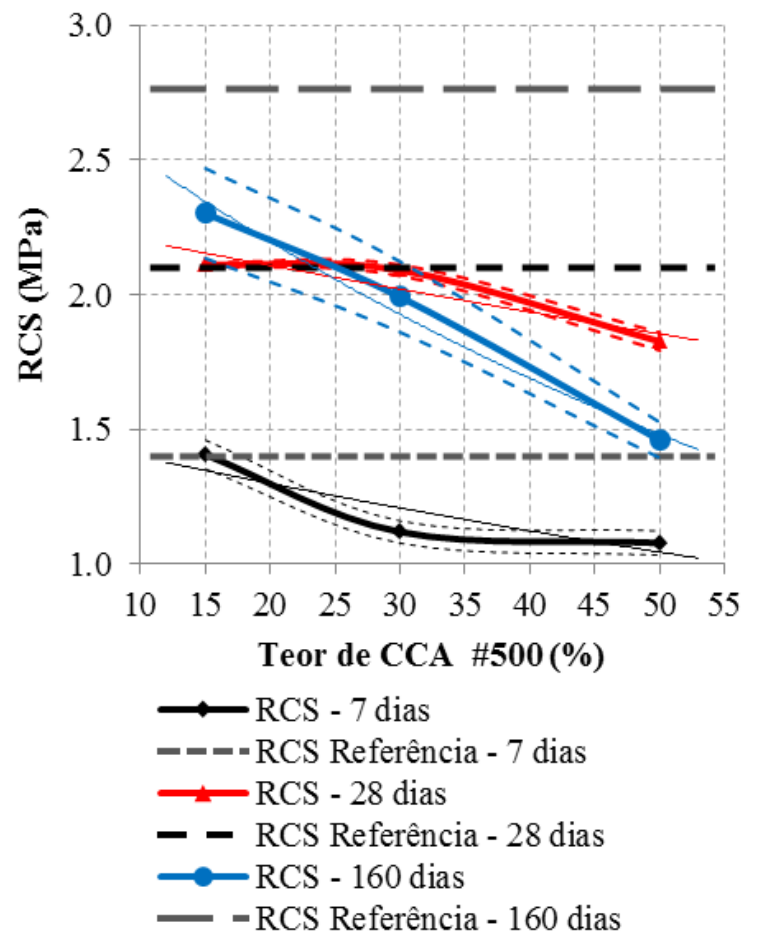

Figura 10: Teor de CCA \#500 x RCS.

Os resultados demonstram que a substituição do cimento Portland pozolânico por CCA faz com que a sua resistência à compressão simples diminua com o aumento do teor de CCA. Os melhores comportamentos são observados com baixo teor de CCA (15\%) e em sua malha mais fina, a CCA \#500, onde com 7 e 28 dias de cura os resultados foram os mesmos das amostras de referência. Para todas as amostras ensaiadas aos 28 dias foi obtido ganho de no mínimo 50\% de resistência em relação aos 7 dias. Fica evidente também a queda abrupta nas curvas das amostras com 160 dias de cura, isso pode ter ocorrido por falta de hidratação das 
amostras, pois no rompimento estas se mostravam pouco úmidas.

Com o intuito de conhecer a real efetividade da CCA nas misturas, foram analisadas as resistências dos corpos de prova com CCA comparativamente àqueles utilizados na estabilização química com cimento Portland, ou seja o teor efetivo de cimento e não mais comparar com o teor de cimento correspondente a cimento + CCA. A determinação do teor de cimento utilizado na pesquisa, foi definido através da curva de tendência das resistências obtidas para 7 e 28 dias de cura, em corpos de prova com 3, 4, 5, e 6\% de cimento Portland. Esses resultados foram utilizados para analisar a efetividade da CCA, conforme mostram as figuras 11 e 12.

Os resultados obtidos mostram que em todas as dosagens ocorre ganho de resistência quando utilizada a CCA como estabilizante químico junto ao cimento Portland. Basta comparar as barras pretas (sem adição de CCA e teor efetivo de cimento Portland que corresponde a segunda coluna da Tabela 5) com as barras azuis e vermelhas em que foi adicionada a CCA (quarta coluna da Tabela 5). Essas variações, sempre positivas, aumentando a resistência entre $8 \%$ e $76 \%$ nas amostras ensaiadas aos 7 dias, e de $6 \%$ a $73 \%$ quando ensaiadas aos 28 dias. Nesta análise, os ganhos significativos ficam por conta das misturas com 50\% de CCA em ambas as idades e finuras de CCA.

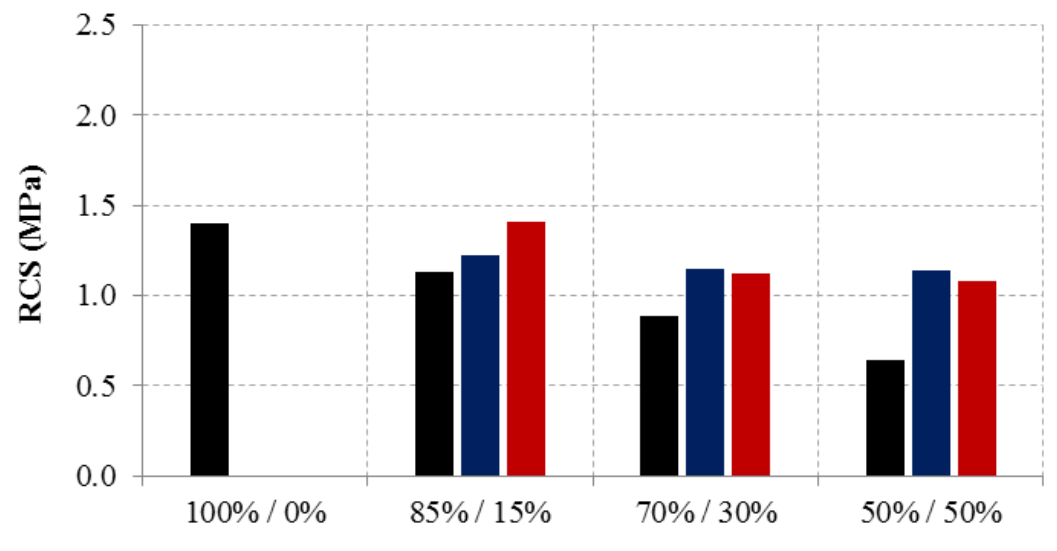

Teores de Cimento / CCA

- Misturas de referência: Somente com cimento Portland

- Misturas com CCA \#325

- Misturas com CCA \#500

Figura 11: RCS: Efetividade da CCA aos 7 dias.

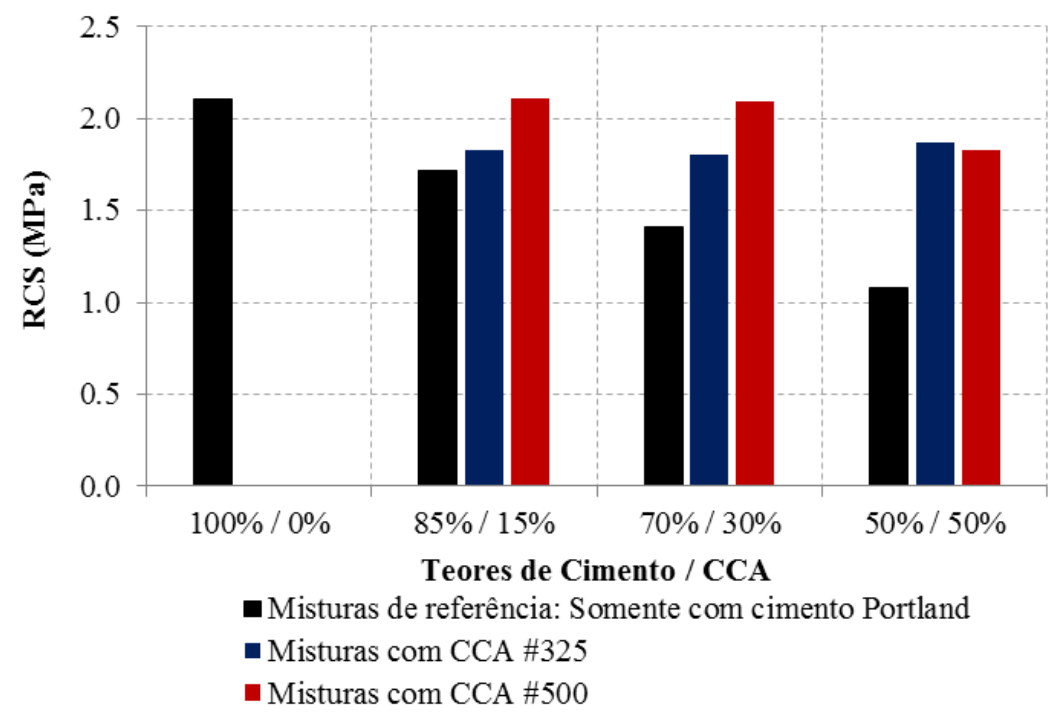

Figura 12: RCS: Efetividade da CCA aos 28 dias.

As figuras 13 e 14 apresentam os resultados de RTCD para as misturas estabilizadas com CCA \#325 e 
\#500, respectivamente. Os resultados obtidos para RTCD foram positivos, houve baixa perda de resistência em comparação às amostras de referência, e um ganho significativo em idades avançadas. Nesse caso, os resultados de ambas as CCAs utilizadas ficaram próximos, com ligeira melhora para CCA\#500 aos 7 e 28 dias, e 160 dias para as amostras com CCA\#325. Nos 160 dias de cura, as amostras com CCA apresentaram entre 20 e 45\% menos resistência que as amostras moldadas somente com cimento, mas ao analisar o ganho de resistência de 7 para 160 dias de cura, as referências obtiveram 300\% de ganho, enquanto as amostras com CCA obtiveram em torno de 350\% para CCA\#325 e entre $250 \%$ e 350\% para CCA\#500, dependendo do teor de cinza utilizado. Os resultados obtidos foram inferiores aos resultados de ensaios de RTCD de misturas com $80 \%$ de material fresado $+20 \%$ de agregados, adicionando cimento Portland (5\%) e CCA (5\%), os resultados aos 28 dias foram superiores à $1 \mathrm{MPa}$, que podem ser explicados pela maior porcentagem de aditivo incorporado [40]. Os mesmos autores apresentam resultados com apenas 5\% de cimento Portaland incorporado, com resultados similares aos obtidos por esta pesquisa.

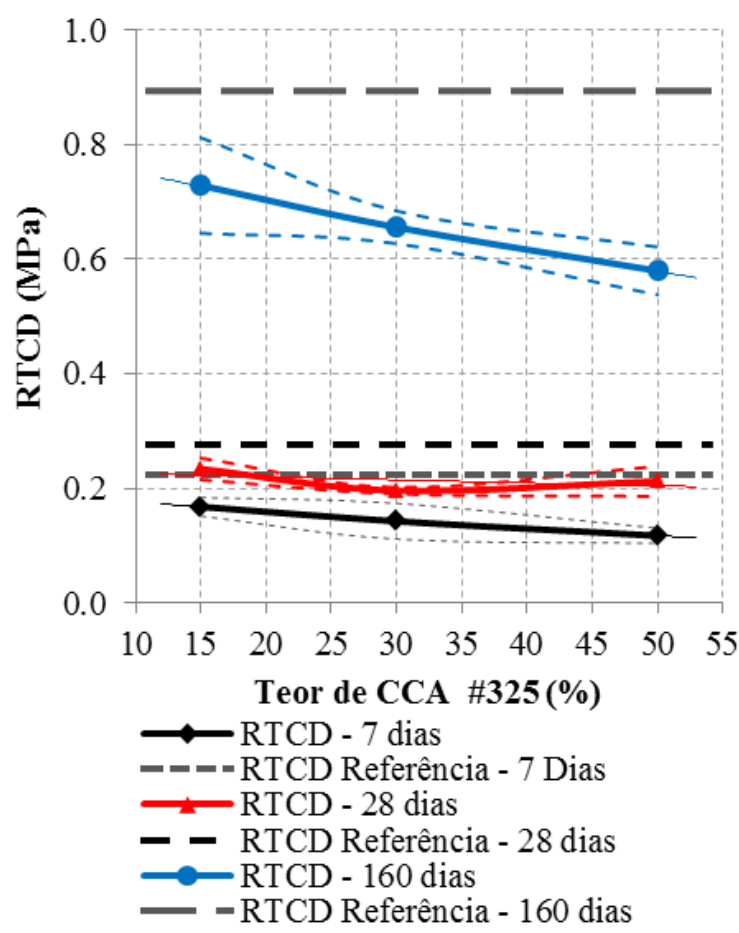

Figura 13: Teor de CCA \#325 x RTCD.

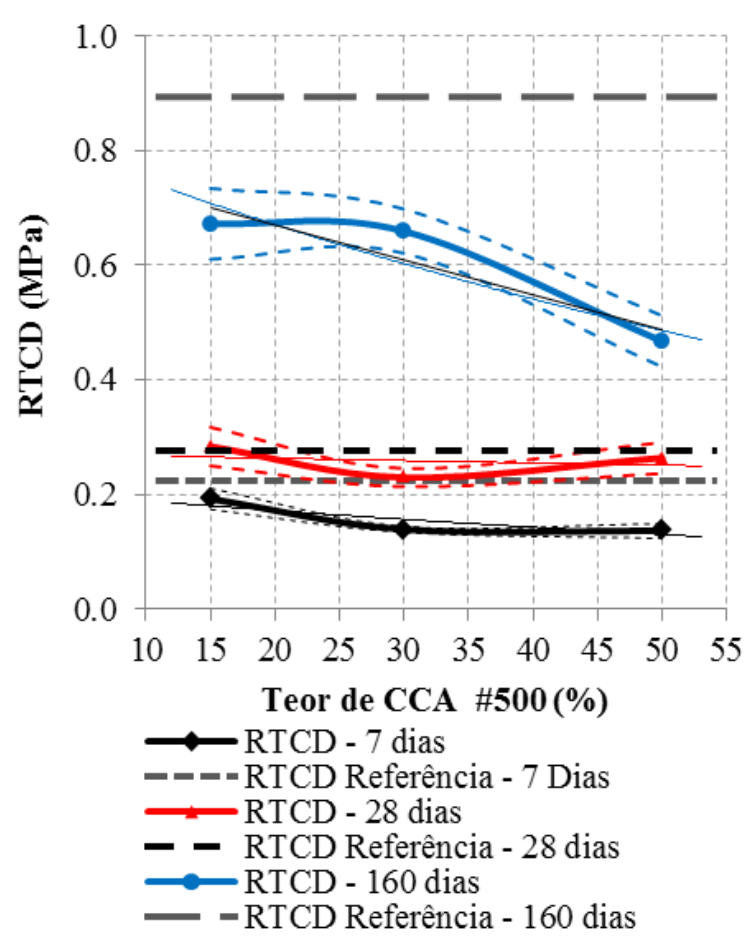

Figura 14: Teor de CCA \#500 x RTCD.

Também foram estimados os valores de resistência à compressão diametral das misturas com apenas cimento Portland como estabilizante químico. Essa análise foi realizada para determinar a efetividade da CCA nesse ensaio, assim como apresentado anteriormente nos resultados de RCS. Com isso é apresentada a tabela 6, que apresenta os teores de cimento Portland nas misturas, e as respectivas resistências à compressão simples e à tração na compressão diametral. Os valores de RTCD de misturas com cimento Portland em teores abaixo de 5,37\% foram determinados a partir da relação RCS/RTCD, pois só foram moldadas amostras para RTCD no teor considerado ideal. Os resultados de RCS e RTCD para misturas com 5,37\% de cimento Portland ja eram conhecidos, com isso foi determinada a relação RCS/RTCD, 16,0\% e 13,2\% para 7 e 28 dias respectivamente. Com essa relação foram estimados os valores de RTCD para as demais misturas. As figuras 15 e 16 apresentam a efetividade da CCA nos resultados de RTCD. 
Tabela 6: Valores de RTCD a partir da relação RCS / RT.

\begin{tabular}{c|c|c|c|c|c}
\hline $\begin{array}{c}\text { TEMPO DE } \\
\text { CURA (DIAS) }\end{array}$ & $\begin{array}{c}\text { CIMENTO } \\
\text { PORTLAND (\%) }\end{array}$ & $\begin{array}{c}\text { CIMENTO PORTLAND NA } \\
\text { MISTURA (\%) }\end{array}$ & RCS (MPa) & $\begin{array}{c}\text { RELAÇÃO } \\
\text { RCS / RTCD }\end{array}$ & RTCD (MPa) \\
\hline 7 & 100 & 5,37 & 1,40 & $16,00 \%$ & 0,22 \\
\hline 7 & 85 & 4,56 & 1,13 & $16,00 \%$ & 0,18 \\
\hline 7 & 70 & 3,76 & 0,89 & $16,00 \%$ & 0,14 \\
\hline 7 & 50 & 2,69 & 0,65 & $16,00 \%$ & 0,10 \\
\hline 28 & 100 & 5,37 & 2,10 & $13,20 \%$ & 0,28 \\
\hline 28 & 85 & 4,56 & 1,72 & $13,20 \%$ & 0,23 \\
\hline 28 & 70 & 3,76 & 1,41 & $13,20 \%$ & 0,19 \\
\hline 28 & 50 & 2,69 & 1,08 & $13,20 \%$ & 0,14 \\
\hline
\end{tabular}

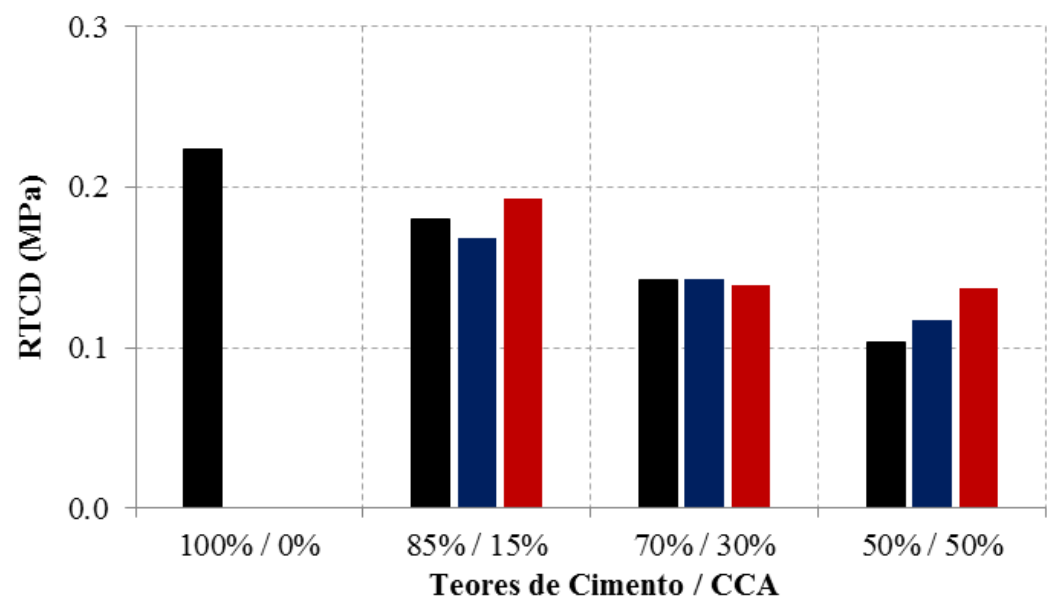

- Misturas de referência: Somente com cimento Portland

- Misturas com CCA \#325

- Misturas com CCA \#500

Figura 15: RTCD: Efetividade da CCA aos 7 dias.

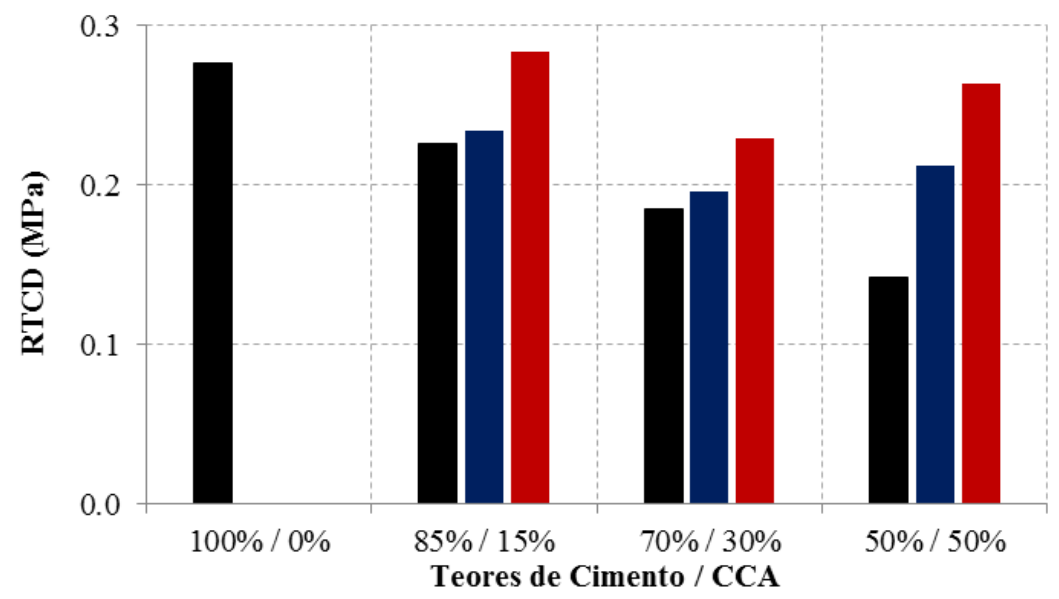

-Misturas de referência: Somente com cimento Portland

- Misturas com CCA \#325

- Misturas com CCA \#500

Figura 16: RTCD: Efetividade da CCA aos 28 dias.

Os resultados mostram baixa variação das resistências aos 7 dias de cura, sendo que o melhor comportamento foi obtido com a utilização de $50 \%$ de CCA, com ganhos de até 32\%. Para as amostras com 15\% e 
30\% de CCA, as variações foram baixas, de -7\% até 6\%. Já os corpos de prova ensaiados aos 28 dias apresentaram melhor comportamento, onde os ganhos de resistência foram positivos em todas as dosagens com CCA. Os relatos na literatura [7, 8, 41] sobre a substituição de cimento Portland por CCA em concreto convencional, ou estrutural, mostram resultados próximos ao obtidos aqui, sendo que os autores apresentam o ganho de resistência com CCA a partir de 28 dias de cura (28 e 91 dias), tempo mínimo necessário para obter resultados satisfatórios devido ao lento processo de hidratação proporcionado pela adição da CCA.

Nas figuras 17 e 18 estão apresentados os resultados de MR para as misturas estabilizadas com CCA \#325 e \#500, respectivamente. As tensões utilizadas na execução desses ensaios, de acordo com a norma ASTM D7369, deve estar compreendido entre 10 e 20\% do valor determinado de resistência à tração (RT). Nessa pesquisa a resistência à tração foi determinada por compressão diametral e os resultados apresentados previamente foram utilizados para determinação dos módulos resilientes, sendo que o valor adotado foi de $10 \%$ da RTCD obtida para cada caso.

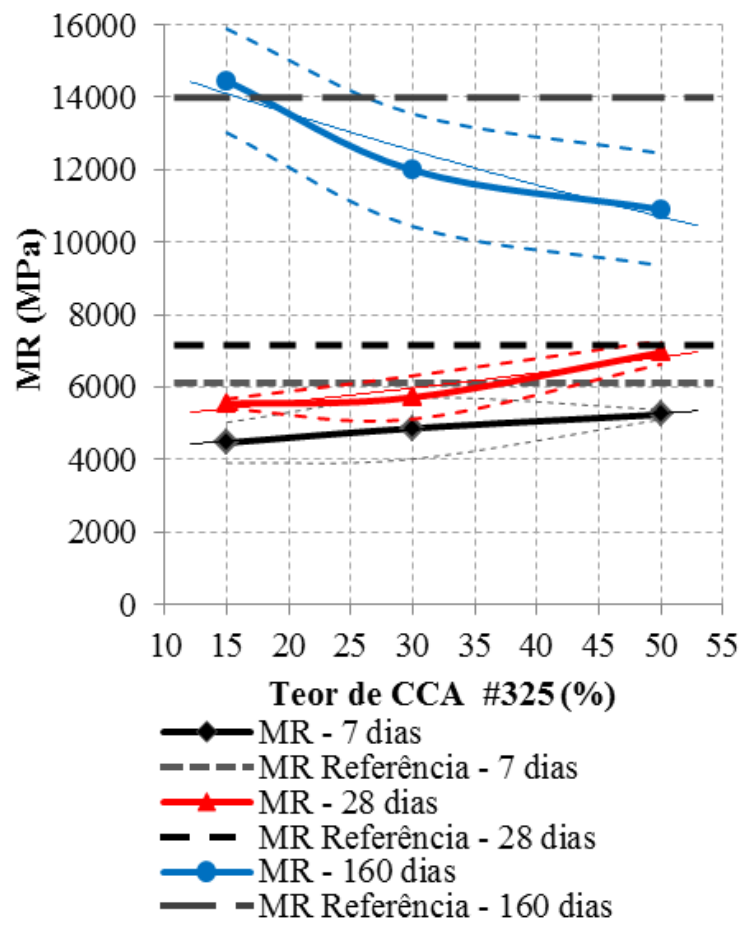

Figura 17: Teor de CCA \#325 x MR.

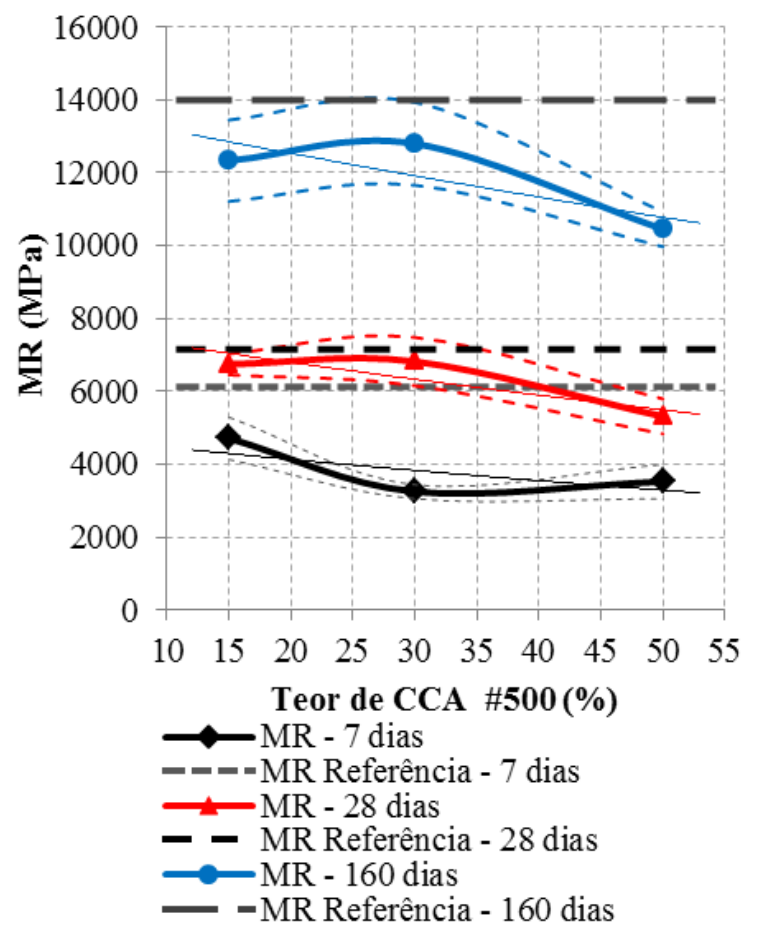

Figura 18: Teor de CCA \#500 x MR.

Os resultados de MR apresentaram valores próximos dos citados por BERNUCCI et al. [42] para materiais graduados tratados com cimento, variando de 6.000 a $12.000 \mathrm{MPa}$. As amostras de referência ficaram em aproximadamente 6.000 MPa para 7 dias, 7.000 MPa aos 28 dias e $14.000 \mathrm{MPa}$ aos 160 dias de cura, o que mostra claramente o aumento da rigidez do material ao longo do tempo. Os corpos de prova moldados com CCA \#325 apresentaram aumento do MR com o aumento do teor de CCA aos 7 e 28 dias, e queda de 14.000 MPa (15\%) para 11.000 MPa (50\%) aos 160 dias, semelhantes aos resultados de resistência mecânica (RCS e RTCD) que justificam um material de menor rigidez. As misturas com resultados mais próximos da referência com cimento ficaram por conta das amostras com 28 dias de cura e CCA \#500. O aumento do MR de 7 para 160 dias variou de $100 \%$ a 300\%, dependendo do caso.

A análise dos resultados de MR é bastante complexa, uma vez que dependendo da estrutura onde será utilizado o material, valores maiores ou menores podem ou não ser tolerados. Desta forma, é necessária uma compatibilização da rigidez entre as camadas que constituem o sistema. As tabelas 7 e 8 apresentam os resultados da relação MR / RT para complementar a análise dos resultados. 
PIRES, G.M.; SPECHT, L.P.; PINHEIRO, R.J.B.P.; PEREIRA, D.S.; RENZ, E.M. revista Matéria, v.21, n.2, pp. 365 - 384, 2016.

Tabela 7: CCA \#325 Relação MR/RT.

\begin{tabular}{l|c|c|c|c|c|c|c|c|c|c|c|c}
\hline CURA (DIAS) & $\mathbf{7}$ & $\mathbf{7}$ & $\mathbf{7}$ & $\mathbf{7}$ & $\mathbf{2 8}$ & $\mathbf{2 8}$ & $\mathbf{2 8}$ & $\mathbf{2 8}$ & $\mathbf{1 6 0}$ & $\mathbf{1 6 0}$ & $\mathbf{1 6 0}$ & $\mathbf{1 6 0}$ \\
\hline TEOR \#325 & Ref. & $15 \%$ & $30 \%$ & $50 \%$ & Ref. & $15 \%$ & $30 \%$ & $50 \%$ & Ref. & $15 \%$ & $30 \%$ & $50 \%$ \\
\hline MR (MPa) & 6122 & 4469 & 4863 & 5246 & 7154 & 5543 & 5719 & 6955 & 13990 & 14456 & 11989 & 10908 \\
\hline RTCD (MPa) & 0,22 & 0,17 & 0,14 & 0,12 & 0,28 & 0,234 & 0,20 & 0,21 & 0,90 & 0,73 & 0,66 & 0,58 \\
\hline MR/RT (adm.) & 27333 & 26614 & 34084 & 44672 & 25872 & 23678 & 29167 & 32765 & 15656 & 19839 & 18287 & 18821 \\
\hline
\end{tabular}

Tabela 8: CCA \#500 Relação MR/RT.

\begin{tabular}{l|c|c|c|c|c|c|c|c|c|c|c|c}
\hline CURA (DIAS) & $\mathbf{7}$ & $\mathbf{7}$ & $\mathbf{7}$ & $\mathbf{7}$ & $\mathbf{2 8}$ & $\mathbf{2 8}$ & $\mathbf{2 8}$ & $\mathbf{2 8}$ & $\mathbf{1 6 0}$ & $\mathbf{1 6 0}$ & $\mathbf{1 6 0}$ & $\mathbf{1 6 0}$ \\
\hline TEOR \#500 & Ref. & $15 \%$ & $30 \%$ & $50 \%$ & Ref. & $15 \%$ & $30 \%$ & $50 \%$ & Ref. & $15 \%$ & $30 \%$ & $50 \%$ \\
\hline MR (MPa) & 6122 & 4710 & 3245 & 3523 & 7154 & 6743 & 6817 & 5311 & 13990 & 12330 & 12794 & 10447 \\
\hline RTCD (MPa) & 0,22 & 0,20 & 0,14 & 0,14 & 0,28 & 0,28 & 0,23 & 0,26 & 0,90 & 0,68 & 0,66 & 0,47 \\
\hline MR/RT (adm.) & 27333 & 24476 & 23290 & 25789 & 25872 & 23759 & 29677 & 20124 & 15656 & 18339 & 19402 & 22360 \\
\hline
\end{tabular}

Ao trabalhar com misturas estabilizadas com cimento, foram obtidos corpos de prova de elevada rigidez. A relação MR/RT permite inferir acerca da compatibilidade entre rigidez e resistência da mistura. Misturas muito rígidas necessitam de uma alta resistência à tração devido a concentração de esforços em seu interior. As tabelas 6 e 7 mostram poucas diferenças entre amostras moldadas com diferentes finuras de CCA, com o aumento do tempo de cura, as amostras apresentaram evolução nos valores de RT, fazendo com que a relação MR/RT diminua, aumentando a capacidade de absorção das energias de deformação. Em valores, de 7 para 160 dias, MR aumentou cerca de $100 \%$, RTCD até $350 \%$, e a relação MR/RT teve quedas de 15 a $60 \%$.

Na prática, materiais estabilizados granulometricamente com adição de cimento, devido a retração durante o processo de cura, pode ocorrer o aparecimento de trincas e em resultado disso, se aplicados em camadas de base, podem levar a reflexão dessas trincas a camada de revestimento. Por esse motivo seria recomendável o emprego em pavimentos invertidos, como material de sub-base, evitando a reflexão das fissuras para o revestimento asfáltico.

\section{CONCLUSÕES}

A partir desta pesquisa, alguns pontos podem ser destacados:

Os resultados de ISC encontrados se mostraram compatíveis com a literatura pesquisada, e também com a orientação das normas brasileiras para utilização de materiais granulares em camadas de pavimentos. A estabilização granulométrica com 30\% de material virgem é bastante efetiva na elevação do ISC (de 56 para 95\% e de 21 para 68\%, para o fresado da BR-290 e ERS-509, respectivamente).

A estabilização química mostrou que resultados satisfatórios foram encontrados com pouco mais de $5 \%$ no teor de cimento nas misturas, o que deve ser validado economicamente para aplicação em campo. A RTCD apresentou relativo crescimento com o tempo, chegando a até 3,5 vezes dos valores em idades iniciais.

Para RCS e RTCD, a substituição de 15\% de cimento por CCA se mostrou eficiente, não havendo queda de resistência para as amostras de referência, ou seja, comparando-se o teor de cimento com o teor total de aglomerante (cimento + CCA). Os valores encontrados foram inferiores ao encontrados por [43, 44], isso pode ter ocorrido pelo fato de os autores terem utilizado menor porcentagem de material fresado, apesar de o teor de cimento incorporado ter sido no máximo 4\%, sem utilização de CCA. Em uma mistura similar apresentada por [40] os resultados de RTCD foram equivalentes, e quando adicionado a CCA, os valores para esse ensaio também apresentaram considerável crescimento.

Os valores de MR obtidos foram superiores aos encontrados por [43], devido ao maior teor de cimento adotada e pela maior presença de material fresado. Devido aos valores elevados de módulo de resiliência, seria interessante o estudo de aplicação desses materiais em pavimentos invertidos, a fim de evitar a reflexão de trincas devido à retração do cimento contido nas misturas. A relação de MR/RT encontrada mostrou evolução positiva nos valores em idades avançadas de cura, aumentando a tenacidade das misturas.

A análise realizada nos ensaios de RCS e RTCD, avaliando a real efetividade da CCA nas misturas, mostraram que no maior teor de utilização da CCA, de 50\%, foram obtidos os melhores avanços. As amostras com maior teor da cinza apresentaram maior variação nos resultados, porém sempre positivas. Essa aná- 
PIRES, G.M.; SPECHT, L.P.; PINHEIRO, R.J.B.P.; PEREIRA, D.S.; RENZ, E.M. revista Matéria, v.21, n.2, pp. 365 - 384, 2016.

lise colabora com a ideia de que as reações químicas entre cimento Portland e CCA ocorreram em maiores proporções, apresentando ganhos significativos na resistência dos corpos de prova.

Desta forma, e suportado pelos resultados laboratoriais apresentados, torna-se evidente o futuro promissor para utilização do material fresado, principalmente com o material fresado estabilizado mecânica e granulometricamente, que aliam de maneira inquestionável o quesito técnico e econômico, com a realização de ensaios mais simples e de resultados imediatos. Nessa pesquisa todas as amostras com adição de cimento e CCA contém 70\% do material reciclado, valor considerado elevado mas que mostrou-se de grande potencial. O reaproveitamento desses materiais se torna de extrema importância pela constante intervenção nas rodovias brasileiras para qualquer tipo de conservação. Nesse contexto, a quantidade de reutilização do material fresado em novos pavimentos asfálticos cresce a tal ponto que já não é uma simples alternativa de apelo ambiental, mas uma prática comum em muitos países ao redor do mundo.

\section{AGRADECIMENTOS}

Os autores agradecem à CAPES pela bolsa de Mestrado do primeiro autor e ao CNPq pela bolsa Pq do segundo autor, bem como ao LMCC/UFSM e ao LAPAV/UFRGS pela condução dos ensaios laboratoriais.

\section{BIBLIOGRAFIA}

[1] DEPARTAMENTO NACIONAL DE INFRAESTRUTURA DE TRANSPORTES, Manual de Pavimentação, Rio de Janeiro, 2006.

[2] CNT, SEST e SENAT, Pesquisa CNT de rodovias, Brasília, DF, Brasil, 2014.

[3] INGLES, O. G., METCALF, J. B. Soil Stabilization: Principles and Practice, 1 ed., Melbourne, Butterworths, 1972.

[4] YODER, E. J., WITCZAK, M. W, Principles of Pavement Design, 2 ed., New York, John Wiley \& Sons Inc., 1975.

[5] VARGAS, M. Introdução à Mecânica dos Solos, 1 ed. São Paulo, Mcgraw - Hill do Brasil, 1977.

[6] VAN IMPE, W. F. Soil Improvement: Techniques and their Evolution, Rotterdam, A. A. Balkema Publishers, 1989.

[7] SHEN, J., AMIRKHANIAN, S., MILLER, J. A. "Effects of Rejuvenating Agents on Superpave Mixtures Containing Reclaimed Asphalt Pavement”, Journal Of Materials In Civil Engineering, v.19, n.5 pp. 376-384, 2007.

[8] AL QADI, I., AURANGZEB, Q., CARPENTER, S. H. "Impact of high RAP content on structural and performance properties of asphalt mixtures”, Research Report FHWA-ICT-12-002, University of Illinois at Urbana-Champaign, 2012.

[9] OLIVEIRA, J. R.M.,SILVA, H.M.R.D, JESUS, C.M.G, et al. "Pushing the Asphalt Recycling Technology to the Limit”, International Journal Pavement Research Technology, v. 6, n.2, pp.109-116, 2013.

[10] ZAUMANIS, M., MALLICK, R.B., FRANK, R. "Evaluation of Rejuvenator's Effectiveness with Conventional Mix Testing for 100\% Reclaimed Asphalt Pavement Mixtures”, Transportation Research Record: Journal of the Transportation Research Board, v.1, n. 2370 , pp. 17-25 2013.

[11] SUNIL, S. MALLESH, K.M., CHANDRASEKARAIAH, T. "Experimental investigations on the performance of bituminous mixes with reclaimed asphalt pavement (RAP) materials (case study Tumkur to Chitradurga-NH4)”, International journal of Research in Engineering and Technology, v. 3, n.6, pp.297-303, 2014.

[12] ZAUMANIS, M., MALLICK, R.B., FRANK, R. "Evaluation of different recycling agents for restoring aged asphalt binder and performance of $100 \%$ recycled asphalt”, Materials and Structures, v.48, n.8, pp. 2475-2488, 2015.

[13] MOHAJERI, M. Hot Mix Asphalt Recycling Practices and Principles. Ph.D. Thesis, Delft University of Technology, 2015.

[14] DUART, M. A. Estudo da Microestrutura do Concreto com Adição de Cinza de Casca de Arroz Residual Sem Beneficiamento, Dissertação de M.Sc., PPGEC/UFSM, Santa Maria, RS, Brasil, 2008.

[15] ISAIA, G. C., et al. "Viabilidade do emprego de cinza de casca de arroz natural em concreto estrutural. Parte II: Propriedades da durabilidade”, In: CINPAR, Córdoba, Argentina, 2010. 
PIRES, G.M.; SPECHT, L.P.; PINHEIRO, R.J.B.P.; PEREIRA, D.S.; RENZ, E.M. revista Matéria, v.21, n.2, pp. 365 - 384, 2016.

[16] ALI, F. H., ADNAN, A., CHOY, C. K. "Geotechnical Properties of a Chemically Stabilized Soil from Malaysia with Rice Husk Ash as an Additive”, In: Geotechnical and Geological Engineering, pp. 117-134, Amsterdam, Holanda, 1992.

[17] ALHASSAN, M. "Potential of Rice Husk Ash for soil stabilization", In: Assumption University of Thailand, v.11, n.4, pp. 246-250, 2008.

[18] PRIETTO, P. D. M., ARNOLD,G.P., BASTOS, C.A.B., et al., "Avaliação experimental de solos quimicamente estabilizados para utilização em bases de estradas de baixo volume de tráfego”, In: $15^{\circ}$ Congresso Brasileiro de Mecânica dos Solos e Engenharia Geotécnica, Gramado, RS, Brasil, 2010.

[19] EDEH, J. E., ONCHE, OSINUBI, K. J., "Rice husk ash stabilization of reclaimed asphalt pavement using cement as additive", State Of The Art and Practice in Geotechnical Engineering, pp. 3863-3872, 2012.

[20] SCHENDEL, C., et al., "Novas alternativas de materiais em vias de pavimentação”, In: IV Salão Internacional se Ensino, Pesquisa e Extensão, Bagé, RS, Brasil, 2012.

[21] DEPARTAMENTO NACIONAL DE ESTRADAS DE RODAGEM, DNER-ME 083/98: Agregados análise granulométrica, Rio de Janeiro, 1998.

[22] DEPARTAMENTO NACIONAL DE ESTRADAS DE RODAGEM, DNER-ME 053/94: Misturas betuminosas - percentagem de betume, Rio de Janeiro, 1994.

[23] ASSOCIAÇÃO BRASILEIRA DE NORMAS TÉCNICAS, NBR 15619: Misturas asfálticas - Determinação da massa específica máxima medida em amostras não compactadas, Rio de Janeiro, 2008.

[24] DEPARTAMENTO NACIONAL DE INFRAESTRUTURA DE TRANSPORTES, DNIT-ES 031/2006: Pavimentos flexíveis - Concreto asfáltico - Especificação de serviço, Rio de Janeiro, 2006.

[25] DEPARTAMENTO AUTÔNOMO DE ESTRADAS DE RODAGEM, DAER/RS - ES - P 16/1991: Concreto Asfáltico, Porto Alegre, 1998.

[26] ASSOCIAÇÃO BRASILEIRA DE NORMAS TÉCNICAS, NBR 5736: Cimento Portland pozolânico, Rio de Janeiro, 1991.

[27] ASSOCIAÇÃO BRASILEIRA DE NORMAS TÉCNICAS, NBR 11579: Cimento Portland - Determinação do indice de finura por meio da peneira $75 \mu m$ (n ${ }^{\circ}$ 200), Rio de Janeiro, 2013.

[28] ASSOCIAÇÃO BRASILEIRA DE NORMAS TÉCNICAS, NBR NM 76: Cimento Portland - Determinação da finura pelo método de permeabilidade ao ar (Método de Blaine), Rio de Janeiro, 1998.

[29] ASSOCIAÇÃO BRASILEIRA DE NORMAS TÉCNICAS, NBR NM 23: Cimento portland e outros materiais em pó - Determinação da massa específica, Rio de Janeiro, 2001.

[30] ASSOCIAÇÃO BRASILEIRA DE NORMAS TÉCNICAS, NBR NM 65: Cimento Portland - Determinação do tempo de pega, Rio de Janeiro, 2003.

[31] ASSOCIAÇÃO BRASILEIRA DE NORMAS TÉCNICAS, NBR 7215: Cimento Portland - Determinação da resistência à compressão, Rio de Janeiro, 1997.

[32] DEPARTAMENTO NACIONAL DE ESTRADAS DE RODAGEM, DNER-ME 162/94: Solos - ensaio de compactação utilizando amostras trabalhadas, Rio de Janeiro, 1994.

[33] DEPARTAMENTO NACIONAL DE ESTRADAS DE RODAGEM, DNER-ME 049/94: Solos: determinação do índice de suporte Califórnia utilizando amostras não trabalhadas, Rio de Janeiro, 1994.

[34] DEPARTAMENTO NACIONAL DE ESTRADAS DE RODAGEM, DNER-ES 180/94: Pavimentação: sub-base estabilizada granulometricamente, Rio de Janeiro, 1997.

[35] DEPARTAMENTO NACIONAL DE INFRAESTRUTURA DE TRANSPORTES, DNIT 136/2010: Pavimentação asfáltica - Misturas asfálticas - Determinação da resistência à tração por compressão diametral - Método de ensaio, Rio de Janeiro, 2010.

[36] AMERICAN SOCIETY FOR TESTING AND MATERIALS, ASTM D7369: Standard Test Method for Determining the Resilient Modulus of Bituminous Mixtures by Indirect Tension Test, Philadelphia, Estados Unidos, 2011.

[37] DEPARTAMENTO NACIONAL DE INFRAESTRUTURA DE TRANSPORTES, DNIT 141/2010: Especificação granulométrica para bases estabilizadas, Rio de Janeiro, 2010.

[38] SILVA, C. F. S. C., Reutilização do resíduo oriundo dos serviços de restauração asfáltica como material alternativo em camadas de pavimentos flexíveis. Trabalho de conclusão de curso de graduação em Engenharia Civil, UNIJUÍ, Ijuí, RS, Brasil, 2012. 
PIRES, G.M.; SPECHT, L.P.; PINHEIRO, R.J.B.P.; PEREIRA, D.S.; RENZ, E.M. revista Matéria, v.21, n.2, pp. 365 - 384, 2016.

[39] PINTO, M. M., CERVO T. C., PEREIRA, D. S. "Reutilização de material fresado em acostamentos como agente regularizador e nivelador”, Revista Pavimentação, v.6, n 23, pp.27-35, 2012.

[40] FONTOURA, Priscilla Rodrigues et al., "Avaliação do comportamento mecânico do material fresado misturado com aglomerantes e adições minerais”, In: XVII Congresso Brasileiro de Mecânica dos Solos e Engenharia Geotécnica, Goiânia, 2014.

[41] SOKOLOVICZ, B. C., Microestrutura e Durabilidade a Cloretos de Protótipos de Concreto com Cinza de Casca de Arroz com e sem Moagem Prévia. Dissertação de M.Sc., PPGEC/UFSM, Santa Maria, RS, Brasil, 2013.

[42] BERNUCCI, L., MOTTA, L. G., CERATTI, J. A. P., et al., Pavimentação Asfáltica: Formação Básica para Engenheiros, 1 ed., Rio de Janeiro, ABEDA, 2008.

[43] TRICHÊS, G., et al., "Caracterização do comportamento mecânico de misturas recicladas com adição de cimento”, In: 42 Reunião Anual de Pavimentação, Gramado, 2012.

[44] FEDRIGO, W., NÚÑEZ, W. P., CERATTI, J. A. P. "Reciclagem de pavimentos com adição de cimento Portland”, In: XXVIII Congresso Nacional de Pesquisa e Ensino em Transporte, Curitiba, 2014. 